Issued by Sandia National Laboratories, operated for the United States Department of Energy by Sandia Corporation.

NOTICE: This report was prepared as an account of work sponsored by an agency of the United States Government. Neither the United States Government, nor any agency thereof, nor any of their employees, nor any of their contractors, subcontractors, or their employees, make any warranty, express or implied, or assume any legal liability or responsibility for the accuracy, completeness, or usefulness of any information, apparatus, product, or process disclosed, or represent that its use would not infringe privately owned rights. Reference herein to any specific commercial product, process, or service by trade name, trademark, manufacturer, or otherwise, does not necessarily constitute or imply its endorsement, recommendation, or favoring by the United States Government, any agency thereof, or any of their contractors or subcontractors. The views and opinions expressed herein do not necessarily state or reflect those of the United States Government, any agency thereof, or any of their contractors.

Printed in the United States of America. This report has been reproduced directly from the best available copy.

Available to DOE and DOE contractors from

Office of Scientific and Technical Information

P.O. Box 62

Oak Ridge, TN 37831

Prices available from (703) 605-6000

Web site: http://www.ntis.gov/ordering.htm

Available to the public from

National Technical Information Service

U.S. Department of Commerce

5285 Port Royal Rd

Springfield, VA 22161

NTIS price codes

Printed copy: A03

Microfiche copy: A01

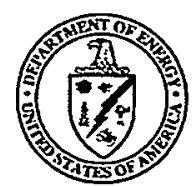




\section{DISCLAIMER}

Portions of this document may be illegible in electronic image products. Images are produced from the best available original document. 
SAND99-1503

Unlimited Release

Printed June, 1999

\title{
Photovoltaic Power for the Nanosat Project
}

\author{
B. H. Rose \\ Advanced Devices and Applications Department \\ Sandia National Laboratories \\ P. O. Box 5800 \\ Albuquerque, NM 87185-0874
}

\begin{abstract}
This report describes the characteristics of photovoltaic arrays that may be suitable for use with nanosatellite electronic systems. It includes a thorough literature search on power management and distribution systems for satellites as small as microsatellites. The major conclusion to be drawn is that it is the total system, including satellite electronic system, photovoltaic systems, peak power tracker and the power management and distribution systems which need to be optimized. An example of a peak power tracker is given, and a novel series connected boost unit is described which might allow the system voltage to be increased if enough photovoltaic panels to operate the systems in real time is impractical. Finally, it is recommended that the development effort be reoriented and expanded to include a peak power tracker and other power management and distribution systems.
\end{abstract}




\section{Acknowledgements}

A critical review of this report by D. W. Palmer is greatly appreciated, and the excellent editorial work on the manuscript by Ginny Edmund is gratefully acknowledged. 


\section{Contents}

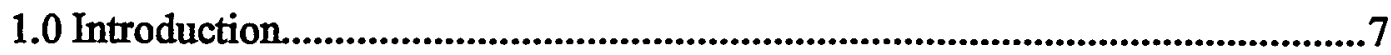

2.0 Photovoltaic Arrays for Nanosatellites ............................................................

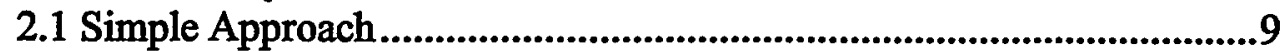

2.2 Hexagon Arrays.........................................................................13

2.3 Octagon Geometry................................................................................19

2.4 General Approach to System Definition................................................23

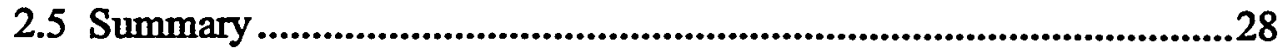

3.0 General Considerations on Satellite Power Conditioning Systems ...............29

3.1 Power Management and Distribution System Functions.....................29

3.2 Requirements.....................................................................................30

3.3 Power Conditioning and Control Systems - General...........................31

3.4 Regulators and Peak Power Tracking................................................34

3.5 Specific Systems..................................................................................35

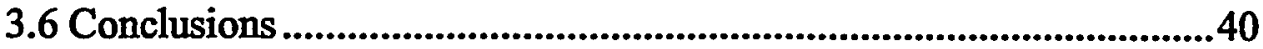

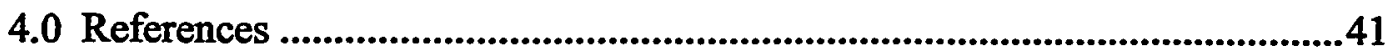

5.0 Appendix - Switch Mode Regulators .......................................................44

\section{Figures}

1. Functional block diagram of a satellite power system .......................................8

2. Seven-inch hexagon and octagon satellite shapes ...........................................9

3. Simple approach to forming a unit PV panel...................................................10

4. Spacings between cells ..............................................................................11

5. Unit panels covering the end of the satellite and foldout ................................12

6. The equilateral triangle that makes up a 7 -inch hexagon ................................14

7. Breakup of the large triangles into 4 smaller triangles......................................15

8. Two strings of series connected PV cells .......................................................16

9. Six cell series connection using the large triangles.........................................17

10. A four-unit array folded out from a stack on the end of the satellite..............18

11. Unit PV panel for the 7-inch octagon........................................................19

12. Example of a foldout configuration for the 7-inch octagonal satellite.............20

13. Alternative foldout configuration which doubles the current to 7 amps.........21

14. The basic octagon shaped unit covering the satellite end ..............................22

15. Calculation of the solar cell area................................................................23

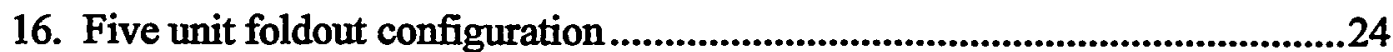

17. Schematic layout of 84 parallel connected strings of 10 series connected $2 \mathrm{~cm} \mathrm{x} 2 \mathrm{~cm} \mathrm{GaAs}$ solar cells .........................................25

18. Plot of junction area required to generate a given current................................26 
19. Plot of the number of cells in series connection against the system voltage.. 27

20. Schematic diagram of a 5-volt, 3-amp system, using $2 \mathrm{~cm} x 2 \mathrm{~cm}$ Si solar cells...............................................................28

21. Schematic diagram of a solar array I-V curve ............................................31

22. Block diagrams of dissipative power and control systems..........................32

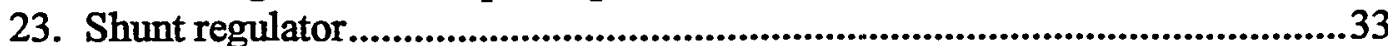

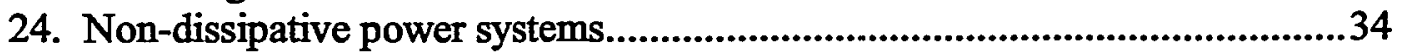

25. Pulse width modulated buck-boost type regulator.......................................34

26. Sunblazer satellite peak power tracker........................................................36

27. Sequence of circuits resulting in an $8 \mathrm{Vdc}$ boost to the input power supply

A1. A linear regulator .........................................................................44

A2. Simplest switching voltage converter.....................................................45

A3. Switch positions for the three basic converters..........................................46 


\section{Photovoltaic Power for Nanosat}

\subsection{Introduction}

This report contains two sections. In the first, several example photovoltaic arrays are presented which might satisfy the current and voltage requirements, were they known at the time of this writing. It contains arrays built from commercially available $\mathrm{GaAs}$ solar cells and arrays of large silicon solar cells of triangular design and meant to fully cover the area of the end of a seveninch hexagon, or octagon. Since they are of a special design, they are not commercially available and will require a new mask set for processing.

Since the current/voltage characteristic for a solar array is nonlinear, an electronic system is required to force the array to operate at the optimum load. This electronic system is called a peak power tracker and is used to force the array to operate at what is called the maximum power point on the current/voltage characteristic. For some systems this electronic circuit also regulates the bus voltage. In addition to extracting the maximum power available from the PV array, this system prevents collapse of the array voltage if the array "sees" an impedance that is too small, which overloads the array. In the second section a variety of power management and distribution (PMAD) systems will be presented for larger satellites, probably none of which will be suitable for a nanosatellite because they are too large and the part count is too high. With one possible exception, most of these systems occupy volumes that are a large fraction of the total satellite volume. This possible exception is a system that was flown in the late 1960s on a mission that had some requirements similar to the nanosat project. The operation of this system is presented in some detail because it is simple and amenable to electronic integration. Finally, an innovative voltage regulator circuit is presented. This system is of interest because it is a way to boost array voltage if we get in the situation where we cannot put out enough solar panels to obtain the required voltage. It amounts to a situation where we may want to trade electronic system volume for reduced PV array volume.

\subsection{Photovoltaic Arrays for Nanosatellites}

Lacking information on specific electronic systems that will be included on the nanosatellite array being proposed, we cannot determine the nature. of the photovoltaic array that would be best be suited to the purpose. However, one can explore the nature of arrays that would cover a range of current and voltage requirements. Given the small dimensions of the satellite, there will be practical limits on the size of the photovoltaic panels which can be deployed. Specifically, we want to avoid situations where the bus voltage and current requirements will require photovoltaic arrays so large that their volume is several times the volume of the satellite before deployment from the mother ship.

We will present a range of system sizes and provide a prescription for determining the approximate size of the PV array, once the system requirements have been determined. We will not deal with the mechanical engineering required to fold out multiple PV panels, as will likely be required. The appropriate time to commence the detailed engineering design coincides with determination of the electrical system requirements. One of the goals of the paper is to demonstrate that the size of the PV system (number of cells) can change drastically with relatively small changes in system current and voltage. 
Another important point is that the size of an array necessary to operate the satellite electronic systems in real time will be substantially larger than the array required to replace the charge in a battery that operates low-duty cycle electronics.

Since cost will be a consideration in the final design, one is immediately attracted to silicon cell technology as being both cheaper and more mature than GaAs cells. However, because it will take roughly $40 \%$ fewer GaAs cells than Si cells to obtain the same voltage, it may not necessarily be true that $\mathrm{Si}$ is the obvious technology choice. GaAs cells have somewhat higher radiation resistance than $\mathrm{Si}$ cells, and in the last decade GaAs space solar cell technology has matured substantially with several companies able to provide qualified space solar cells. Thus, there may be positive aspects to GaAs cell technology that outweigh their higher unit cost.

A functional block diagram of a typical satellite power system, containing control subsystems, is shown in Figure 1.

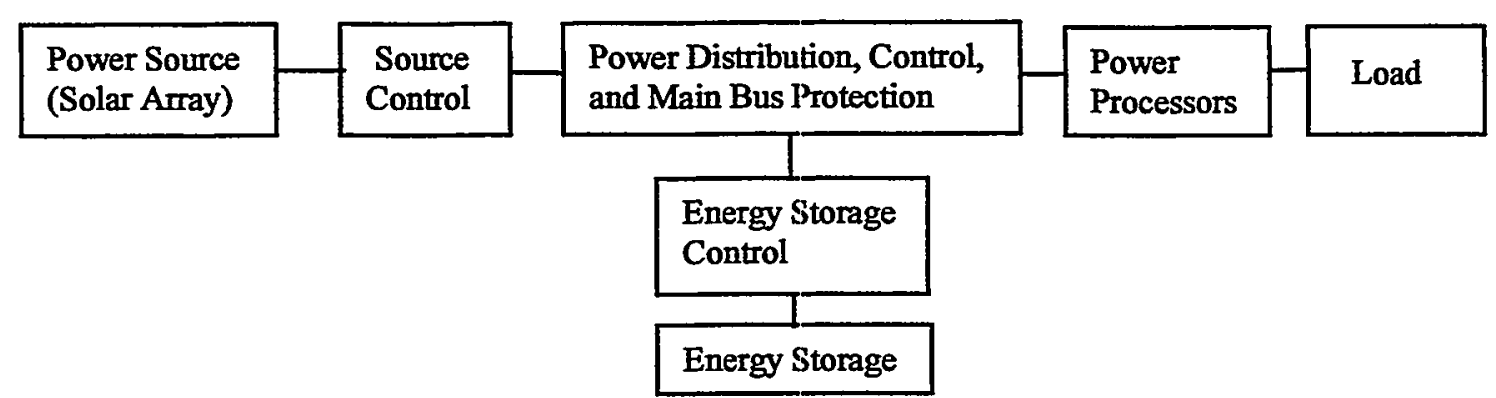

Figure 1. Functional block diagram of a satellite power system. Taken from Space Vehicle Design, by Michael D. Griffin and James R. French, American Inst. Aeronautics and Astronautics, Inc., Washington, D.C., 1991, p. 400.

For the nanosatellite program, the requirements for these subsystems are in the process of being determined at the writing of this document. Therefore, the scope of this discussion will be confined to a range of photovoltaic arrays, based on the sizes of the satellites. The power to operate all the control electronics systems must come from the PV array, so the lower the power consumed the better. The purpose here is to provide an estimate of the sizes and geometric arrangements of the arrays necessary to generate a variety of power levels (bus voltage and current levels).

As a first cut, we will assume a hexagon shape and an octagon shape for the satellite whose minimum dimension is seven inches, as shown in ligigure 2. 

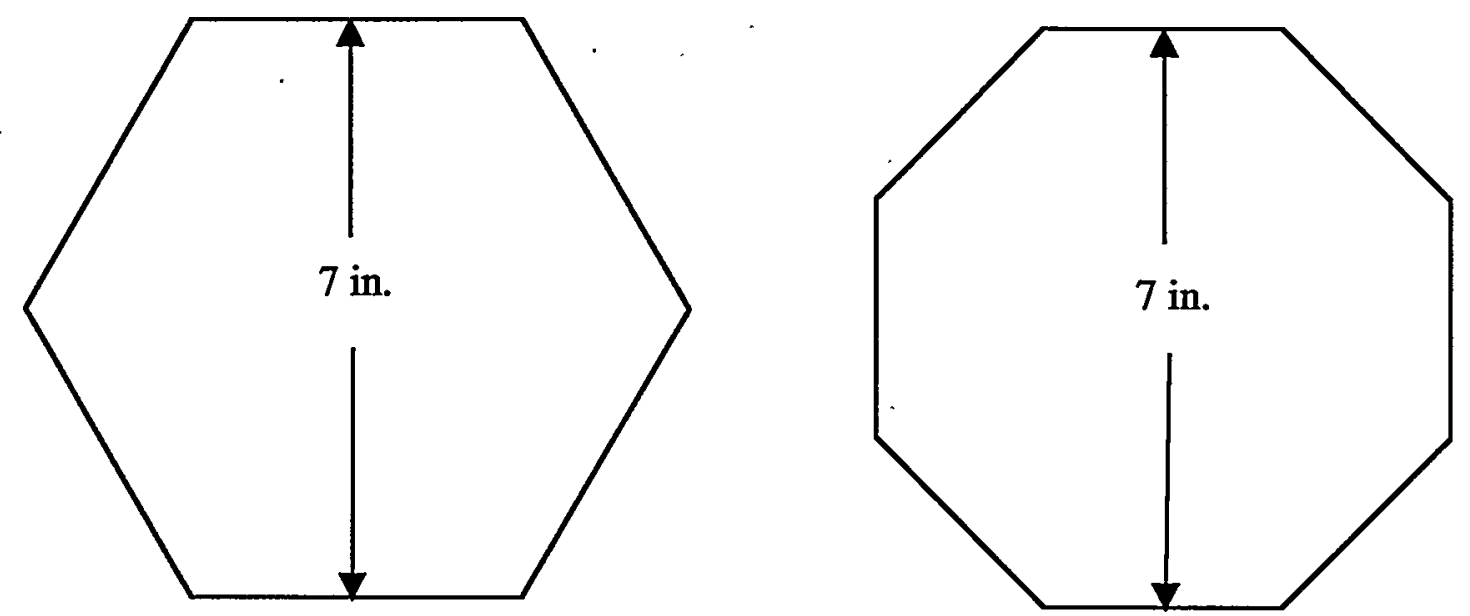

Figure 2. Seven-inch hexagon and octagon shapes for the satellites.

\subsection{Simple Approach}

Perhaps the simplest and least expensive approach to building suitable arrays for the nanosat program is to purchase commercial, qualified GaAs solar cells from existing suppliers, such as Spectrolab, Inc. In this approach no attempt is made to completely cover the end of the satellite with photon absorbing PV cells. We simply take a rectangular piece of plastic whose width is equal to the length of the side of the hexagon and whose length is seven inches, and fill it with $2 \mathrm{~cm} \times 2 \mathrm{~cm}$ solar cells. Such an arrangement is shown in Figure 3. The outer (blue) rectangle represents the thin sheet of plastic, containing metallization for power and ground, plus metal pads (white squares) to mount the cells on. If we wire the seven cells in a column in series, the photovoltages add giving about 7 volts for $\mathrm{GaAs}$ and about 4 volts for Si cells. To do this, we need to fix a conducting path from the bus bar on top of one cell to the metal pad where the adjacent cell is mounted. The approach to mounting the cells on the contact pads will depend on the thermal characteristics of the thin plastic. It may be that the cells will have to be mounted using a conductive adhesive.

If we use $30 \mathrm{~mA} / \mathrm{cm}^{2}$ for the short circuit current density generated by the AM0 space spectrum, then the current in one column of cells would be roughly $120 \mathrm{~mA}$. The AM0 current density may be as much as $34 \mathrm{~mA} / \mathrm{cm}^{2}$ for Si [1], and $32 \mathrm{~mA} / \mathrm{cm}^{2}$ for GaAs [2], so our current estimate will be a lower limit. For the panel in Figure 3, if we wire all four columns in parallel, the current generated is then $0.48 \mathrm{Amps}$ at 7 volts, or 4 volts for $\mathrm{Si}$ cells. 


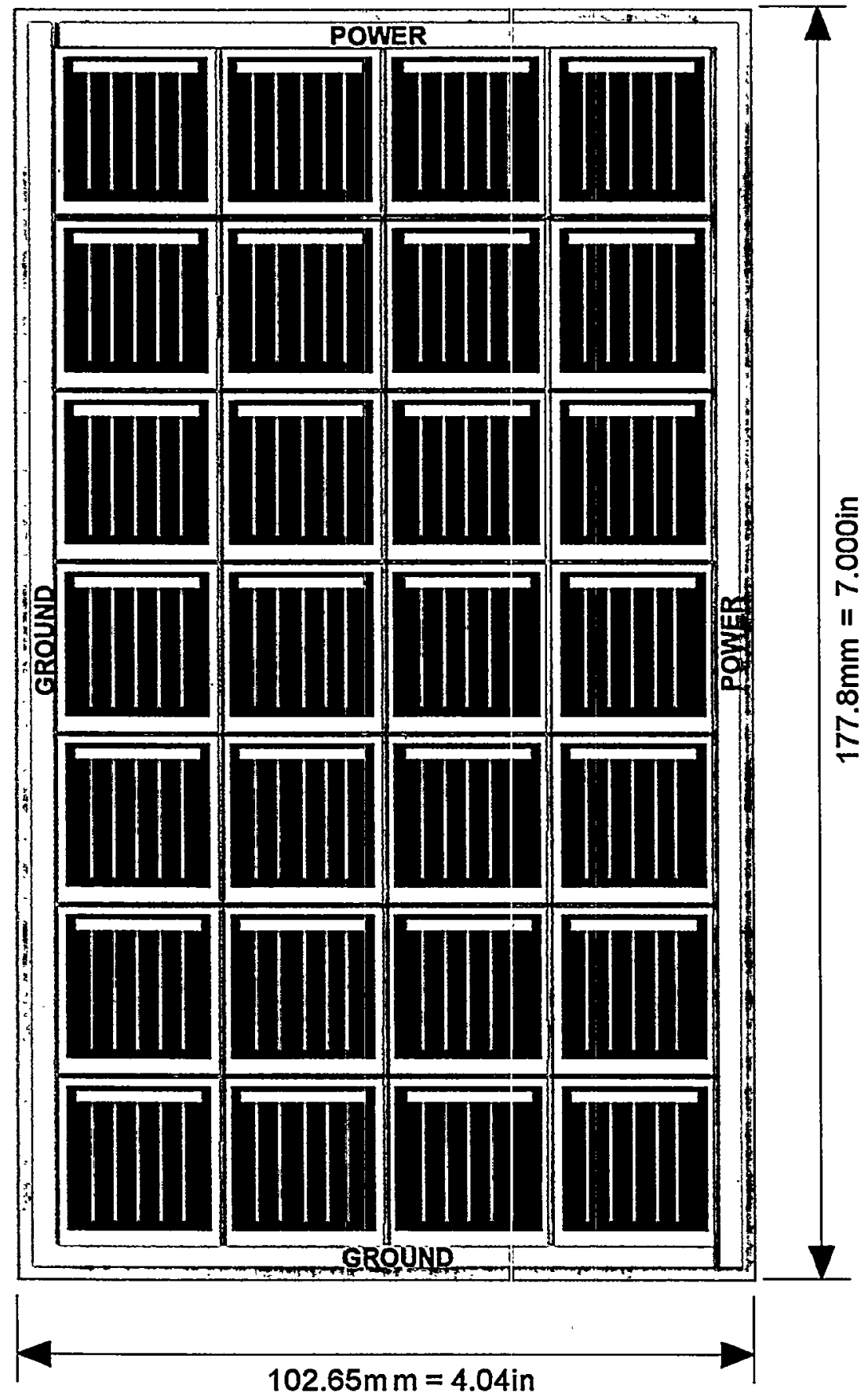

Figure 3. Simple approach to forming a unit PV panel. The cells are commercially available, $2 \mathrm{~cm} \times 2 \mathrm{~cm}$ cells of either Si or GaAs material.

Figure 4 shows a pair of cells with the following dimensions: $1 \mathrm{~mm}$ between cell mounting pads, $1 \mathrm{~mm}$ from cell edge to the mounting pad edge on three sides, and $2 \mathrm{~mm}$ on the third side. This is to allow room to connect one cell to the next. 


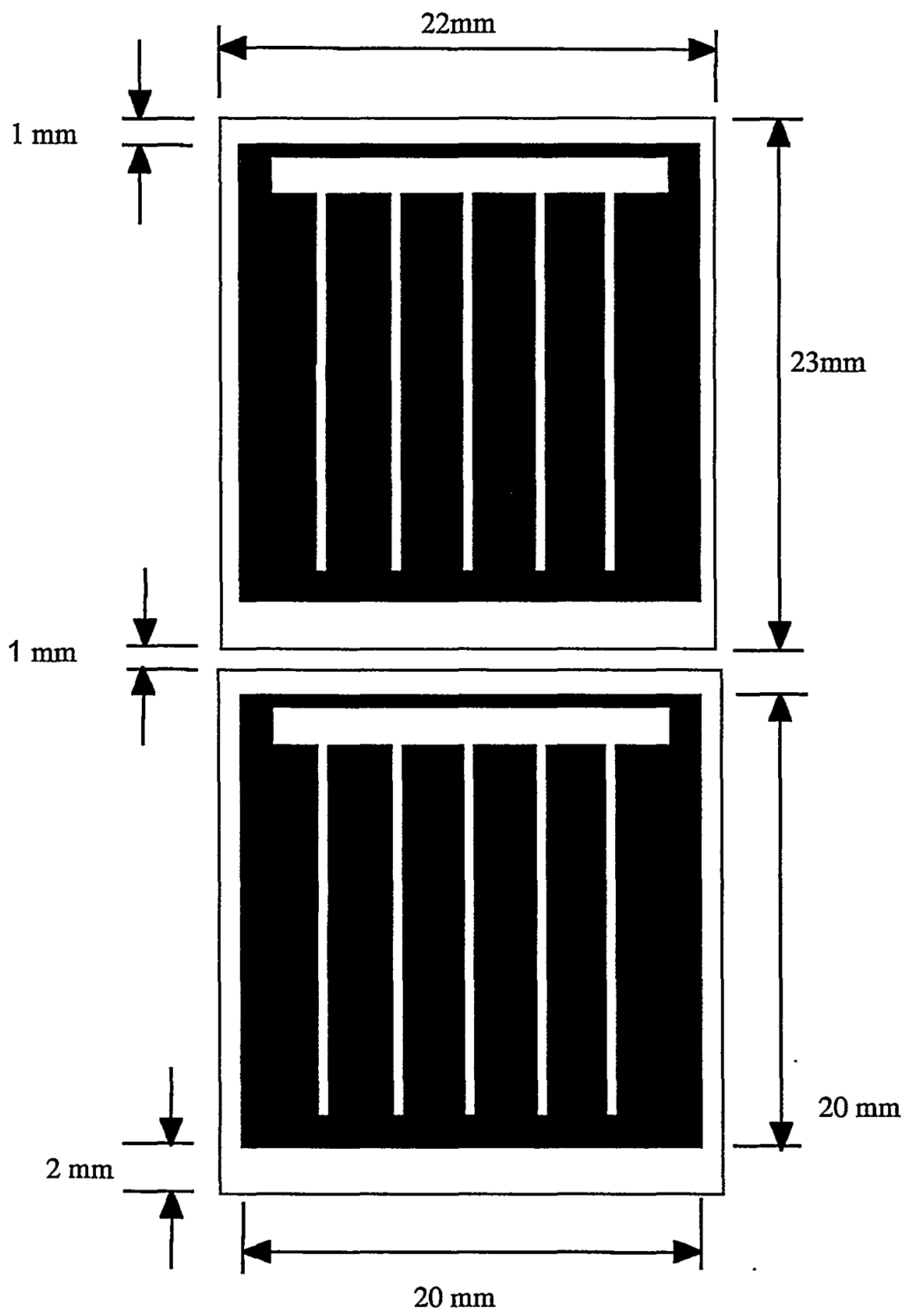

Figure 4. Spacings between cells. The dark area represents the cell, and the enclosed white space represents the metallization contact pad. 
In Figure 5 we show a schematic diagram of the unit arrays spanning the distance from flat side to flat side across the hexagon shaped end of the satellite and how they would look after being folded out. Whether the unit arrays are face up or face down depends on the mechanism of foldout. If the folding out is anchored from each flat side, the unit arrays would have to be face down, not as shown in Fig. 5.

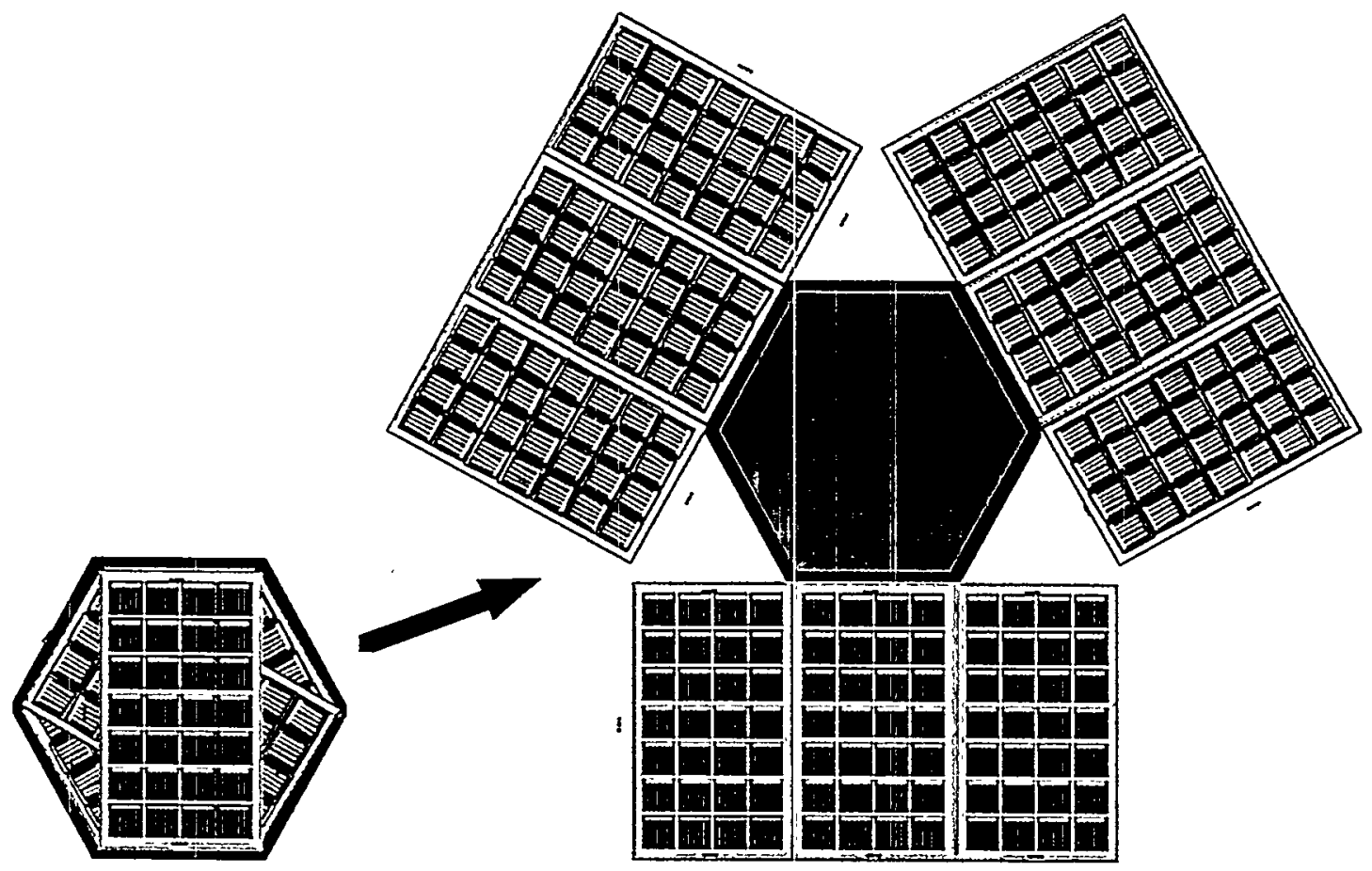

Figure 5. Unit panels covering the end of the satellite and foldout.

If all panels are connected in parallel, the system would generate 4.3 amps at 7 volts using GaAs solar cells.

We should also examine the possibility of just covering the whole satellite surface with PV panels. If enough current can be obtained, this might obviate the need to fold out panels, as in Fig. 5. Suppose the satellite is seven inches long. The panels of Fig. 3 are designed to fit across the seven-inch dimension of the end of the satellite, so one of these panels will exactly fit on each facet of the hexagonal volume. Further, to cover the lateral surface area of hexagonal volume, only six panels are needed, whereas Fig. 5 contains nine. The short circuit current from normal AMO illumination for one of these panels is expected to be about a half an amp. The problem is immediately obvious, if one panel is under normal illumination, the other two on the same side are under oblique illumination, and the panels on the opposite side are in the dark. In this orientation it would be surprising if the current even approached one amp, instead of the 4.3 amps expected from 
the normal incidence of Fig. 5 . The worst case orientation is where the sun's rays are parallel to a line joining two vertices of the hexagon. Here, two panels are in the dark, two panels are receiving only grazing incidence photons, and two are receiving photon flux at an angle of incidence of $30^{\circ}$ (with the normal to the facet). It is well known that the short circuit current is a function of the angle of incidence. Thus, we would not want to use this array configuration unless the PV array requirements were such that only small currents were needed to make up for low duty cycle drain on the batteries. These same arguments hold for octagon geometry also, and the effect is larger for octagons than for hexagons.

\subsection{Hexagon Arrays}

If the shape of the nanosatellite is hexagonal, more efficient use of the space available would be to make the cells triangular. A regular hexagon can be formed out of six equilateral triangles. Thus, almost all the available area on the end of the satellite could be covered with photon absorbing cells. There would be essentially no unused space. The intent here would be to minimize the number of array units in the stack that have to be folded out, which saves weight. Thus, for both the hexagon and octagon geometries, we will make the calculations using triangular PV cells. For the hexagon geometry, a single unit array will be made up of six equilateral triangular cells wired in series so that the voltages will add. Thus, if using conventional $\mathrm{Si}$ cells, whose open circuit voltage would be approximately 0.6 volt, a single unit array would develop about 3.6 volts under AM0 illumination. If we could make these cells from $\mathrm{GaAs}$ junctions, whose open circuit voltage is about one volt, the unit array would generate about 6 volts. Although GaAs cells may be somewhat more expensive, large weight savings can be obtained because the optical absorption coefficient is much larger compared to Si cells, allowing us to thin the cells to a few tens of microns. GaAs space solar cell technology has matured substantially in the last decade or so. This option should be investigated.

The next task is to estimate the short circuit current which could be expected from a unit array. This is obviously a junction-area dependent quantity, whereas the open circuit voltage is not, as long as the area is large enough to generate sufficient light generated current. For the junction areas we are considering here, the areas are large enough that low current will not decrease the open circuit voltage. Since we are only trying to roughly estimate the sizes of PV converter area necessary to operate various satellite systems, we will adopt the AM0 short circuit current density value of $30 \mathrm{~mA} / \mathrm{cm}^{2}$ used above. Since all the electrical systems have not been defined, we can make a more refined calculation later.

Figure 6 shows the equilateral triangle of the hexagon structure calculation. The larger triangle (light yellow) represents a metallization pad and the blue triangle represents the solar cell mounted on it. It has been assumed that the cell lies $1 \mathrm{~mm}$ inside the metal pad. This cuts exactly $4 \mathrm{~mm}$, or $0.16 \mathrm{in}$, off the length of the triangle side. The area of the large triangle is thus $7.07 \mathrm{in}^{2}\left(45.6 \mathrm{~cm}^{2}\right)$ and the area of the cell is $6.52 \mathrm{in}^{2}\left(42.05 \mathrm{~cm}^{2}\right)$, almost $8 \%$ less. Then the short circuit current would be $30 \mathrm{~mA} / \mathrm{cm}^{2} \times 42.05 \mathrm{~cm}^{2}=1.26$ amps. Note that we have not placed a current collecting grid on the cell. By using an experimental number for the short circuit current, the percentage shadowing by a metal grid has already been taken into account. We are assuming that we can duplicate the appropriate grid metallization. These are clearly large solar cells, and while it would probably be possible to fabricate a cell this large with decent yield in $\mathrm{Si}$, doing so in $\mathrm{GaAs}$ technology is likely stretching the state of the art. However, because of the properties of the hexagon shape, each of the equilateral triangles can be divided up into four smaller equilateral triangles, which could be wired in parallel, to produce the same voltage for the unit array. The current would be less because of the dead space increase, but probably not more than $10 \%$ less. 


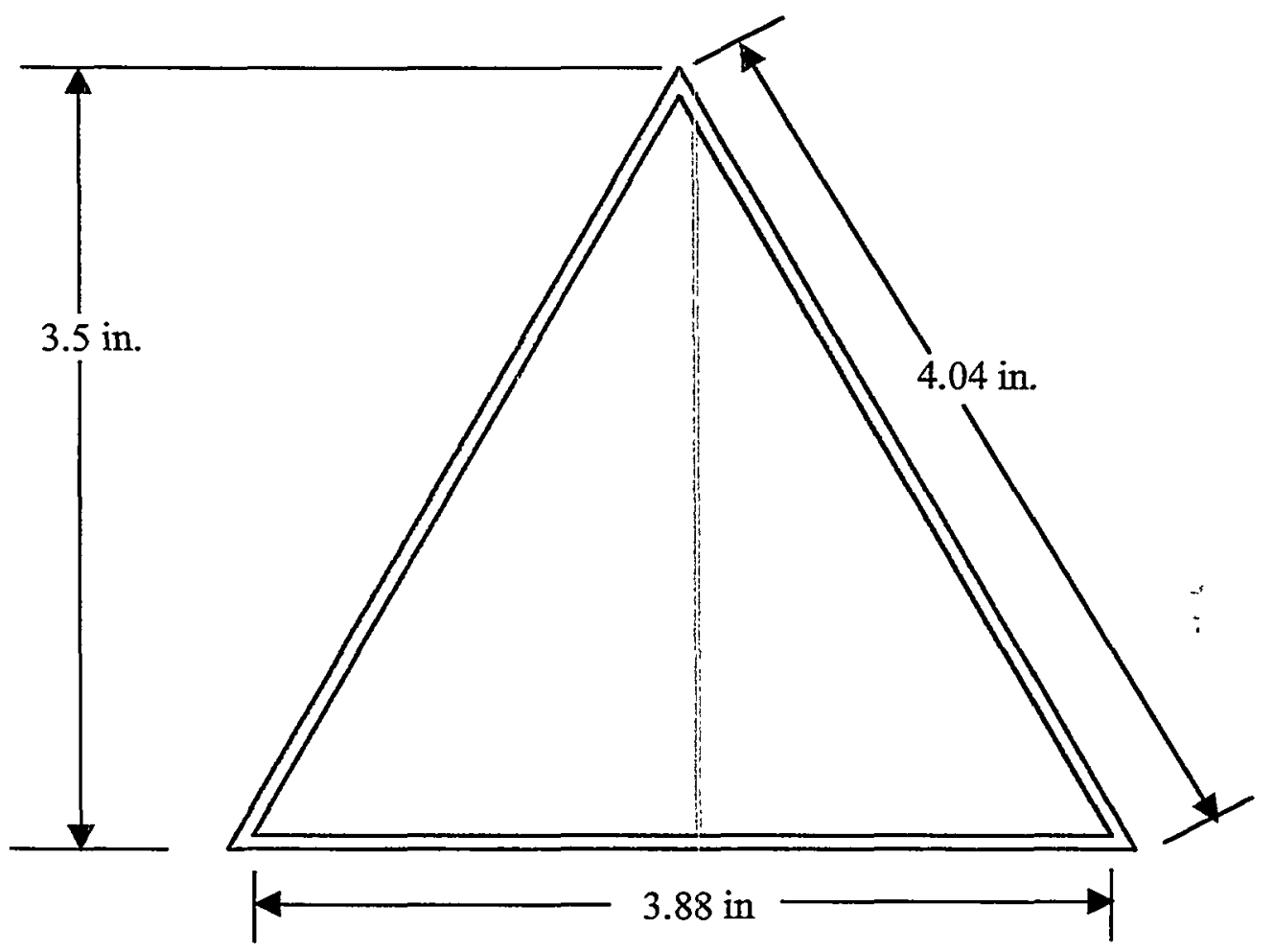

Figure 6. The equilateral triangle that makes up a 7-inch hexagon.

Then connecting the midpoints of each large triangle generates a total of 24 triangles. These can be wired up in several configurations to produce several combinations of current and voltage. Figure 7 shows the breakup of a 7-inch hexagon into 24 smaller triangles, each a little less than 5 $\mathrm{cm}$ on a side. Cells this size can probably be made from GaAs.

One possible wiring configuration is shown in Figure 8. Here the 12 cells in each half of the hexagon are wired in series to produce two strings that generate about 12 volts each. Using the cell area, the short circuit current would be expected to be approximately $330 \mathrm{~mA}$. 


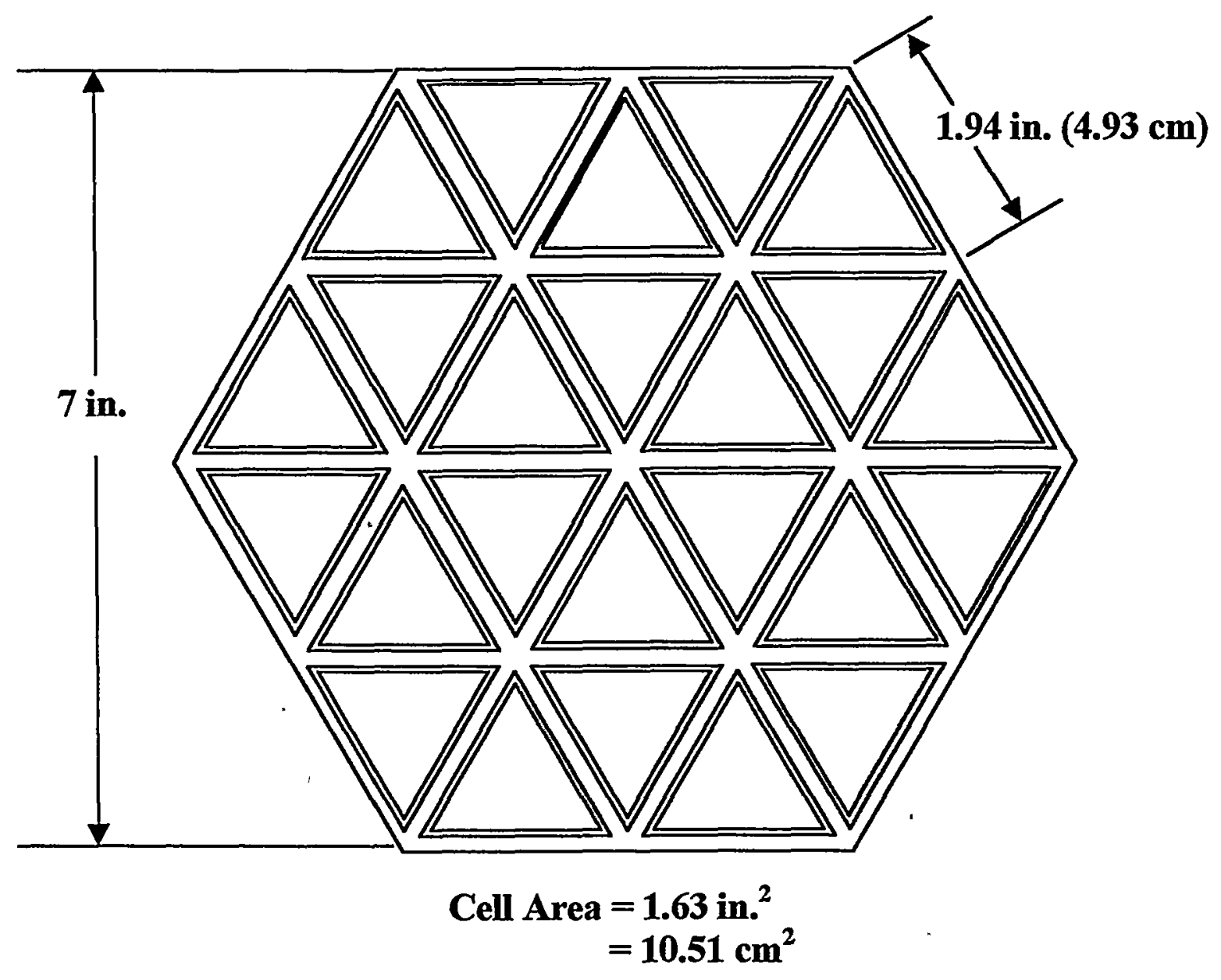

Figure 7. Breakup of the large triangles into 4 smaller triangles. 


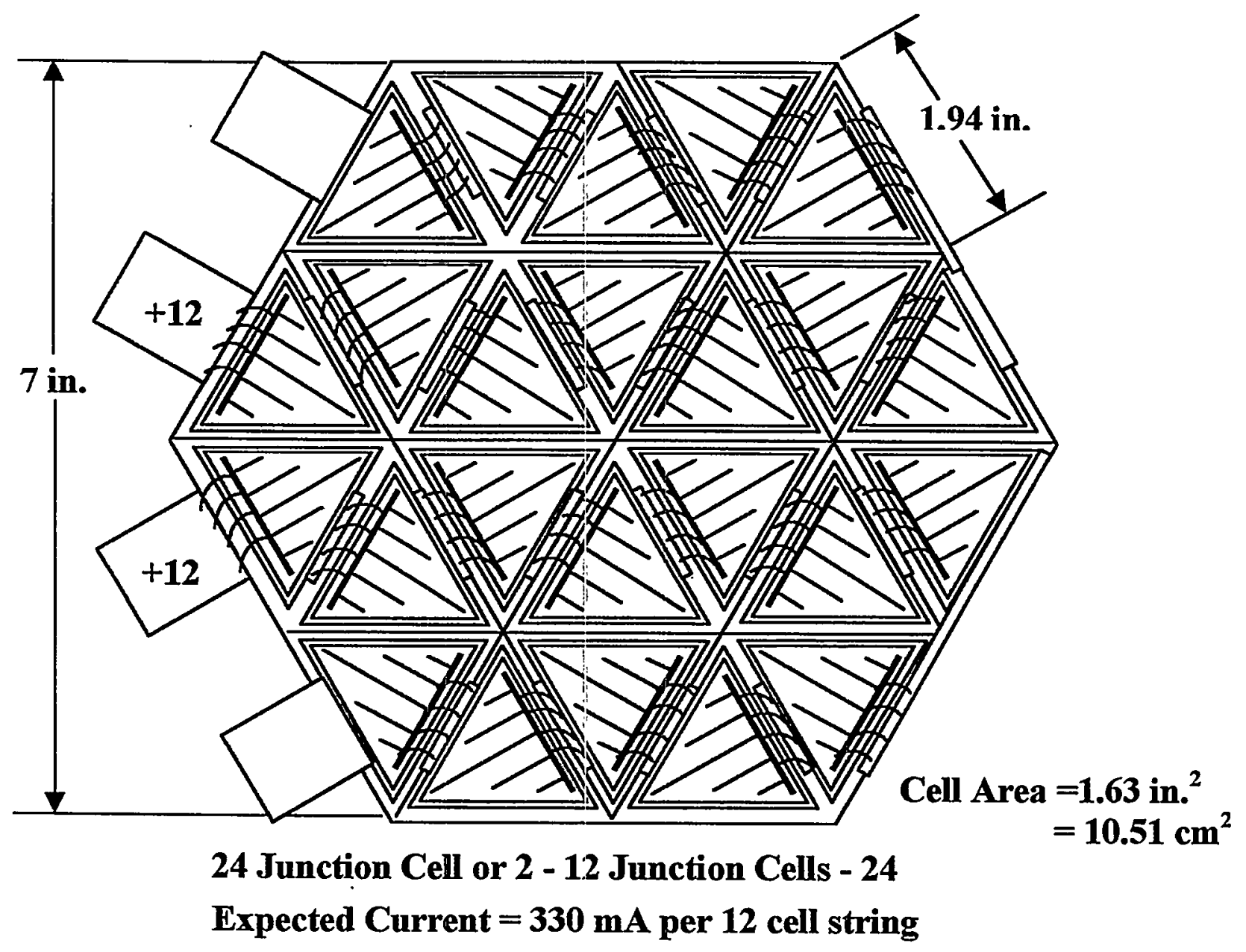

Figure 8. Two strings of series connected PV cells. With GaAs cells, the string voltage would be 12 volts. 
Figure 9 shows the six large cell triangles from Fig. 6 in a series connection. With Si cells, the array voltage would be approximately 3.5 volts and the array current would be about 1.26 Amps.

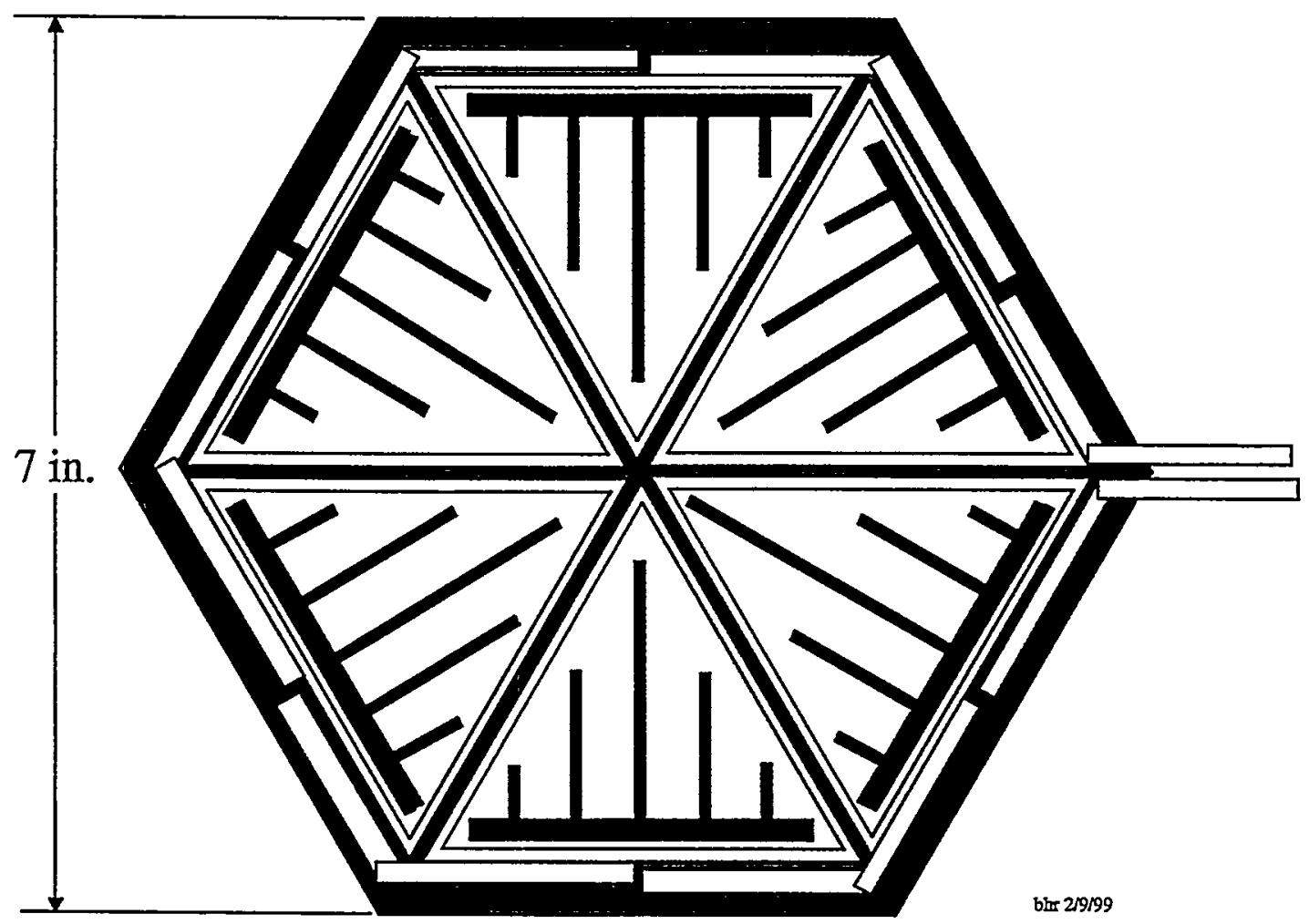

Figure 9. Six cell series connection using the large triangular cells.

As an example of a multiple array which could be folded out once in orbit, Figure 10 is a fourunit array which would generate about 5 amps at 3.6 volts if all four units were wired in parallel. On the other hand, if the end of the satellite is required to be uncovered to be available for other functions, only three units would be folded out. The short circuit current would then be about 3.7 amps at the same 3.6 volts. If more current were needed, three more foldouts could be done, one for each initial unit. This would approximately double the current to 7.4 amps.

It is being assumed that solar arrays large enough to operate all systems on the satellite in real time are required. However, since they will be used in conjunction with a battery, this is not necessarily the case. For example, if a thin battery in the shape of a hexagon is placed on the end of the satellite, it could be charged by wiring all unit arrays to it. If the time average drain from the battery is small compared to the current generated by the solar arrays, then we can reduce the number of unit arrays that are folded out. Whether this is an option cannot be decided until the final electronic system design is obtained. 


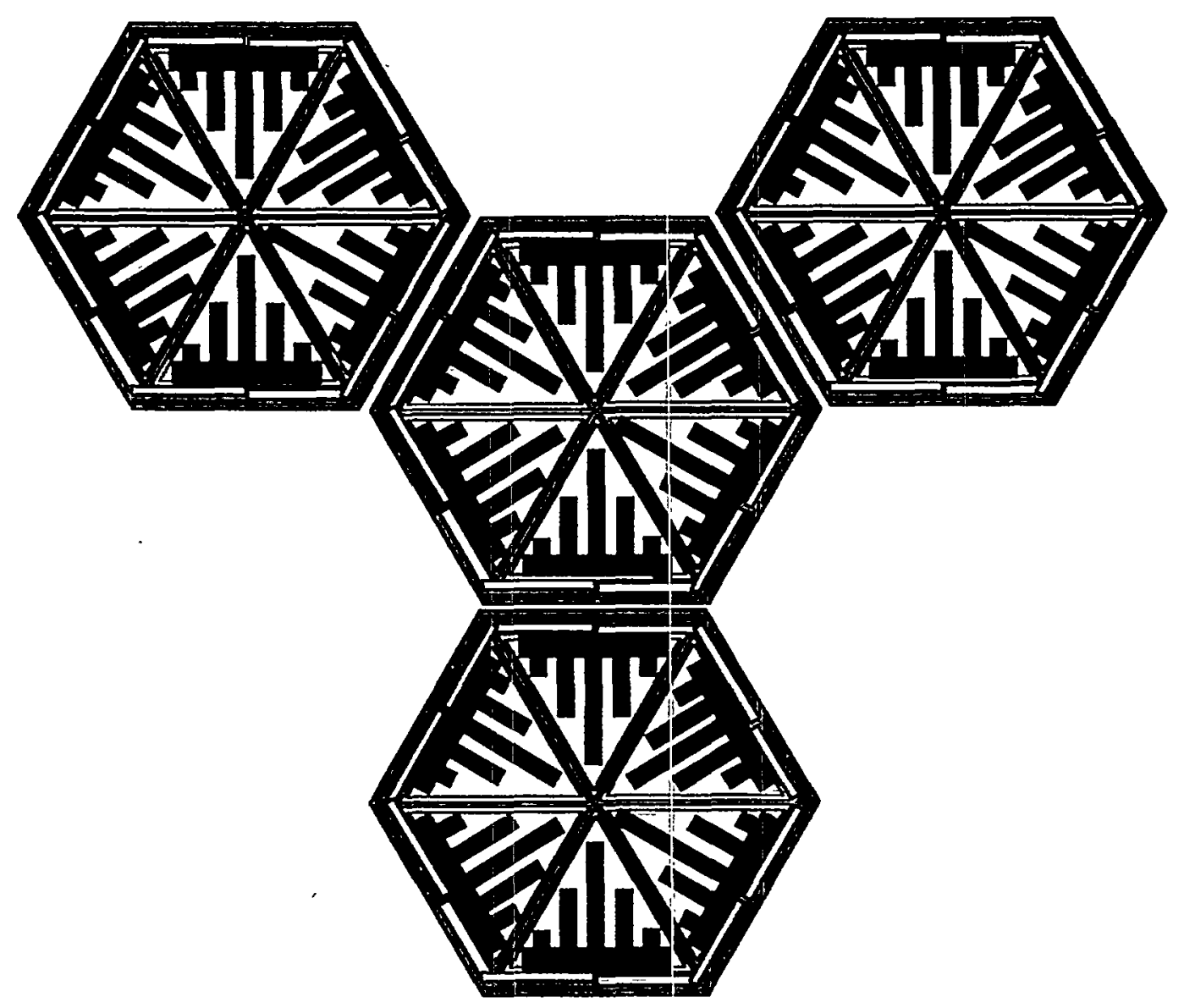

Figure 10. A four-unit array folded out from a stack on the end of the satellite. The short circuit current would be about 5 amps at 3.5 volts. The center unit covers the satellite end. The satellite end could be left uncovered for other functions. The resulting three unit arrays would have a short circuit current of approximately 3.75 amps at the same 3.5 volts.

It should be emphasized that the metal grid lines in Fig. 10 are schematic only. They occupy far too much of the cell surfaces. In practice they will occupy only about $5 \%$ of the cell surfaces. In the process of reducing the size of the pictures, all dimensions were apparently not decreased uniformly.

We would also point out that, while the metal grid lines on individual triangular cells will probably not have to be electroplated to increase the line thickness, if the current from several unit arrays is collected, the trunk current carrying wire will have to be fairly robust so that a minimal part of the array voltage is dropped in the resistance. For example, to carry a current of 6 amps a distance of $30 \mathrm{~cm}(\cong 1 \mathrm{ft}$ ) in a copper wire (resistivity $=1.673 \mu \Omega \mathrm{cm}$ ), it would have to be approximately $2 \mathrm{~mm}$ in diameter in order for the voltage drop to be less than $10 \mathrm{mV}$. Even the bus bars that carry the current from a top contact of one cell to the bottom contact of the next in Fig. 9, will have to be thick. If the length around one corner of the hexagon is $10 \mathrm{~cm}$, assuming the width of the conductor is $3 \mathrm{~mm}$, it would have to be at least $70 \mu \mathrm{m}$ thick to keep the voltage drop under $10 \mathrm{mV}$. Further, the wires connecting the cells to the bus bars in the series connection, as shown in Fig. 8, are only schematic. They will be solid bus bars soldered to the main current carrying bus on the cells to the bus bar off the cell. All these measures are not technologically difficult. 


\subsection{Octagon Geometry}

If the shape of the satellite is octagonal and we use the simple approach with rectangular unit arrays, the width of the array is smaller because the flat side is smaller for the octagon. Keeping the same 7-inch distance from flat side to flat side, the flat side length is 2.9 inches, or $73.6 \mathrm{~mm}$. This barely leaves room for three cells across rather than four for the hexagon. Using the same cell to cell spacing as Fig. 4, the unit panel is as shown in Fig. 11.

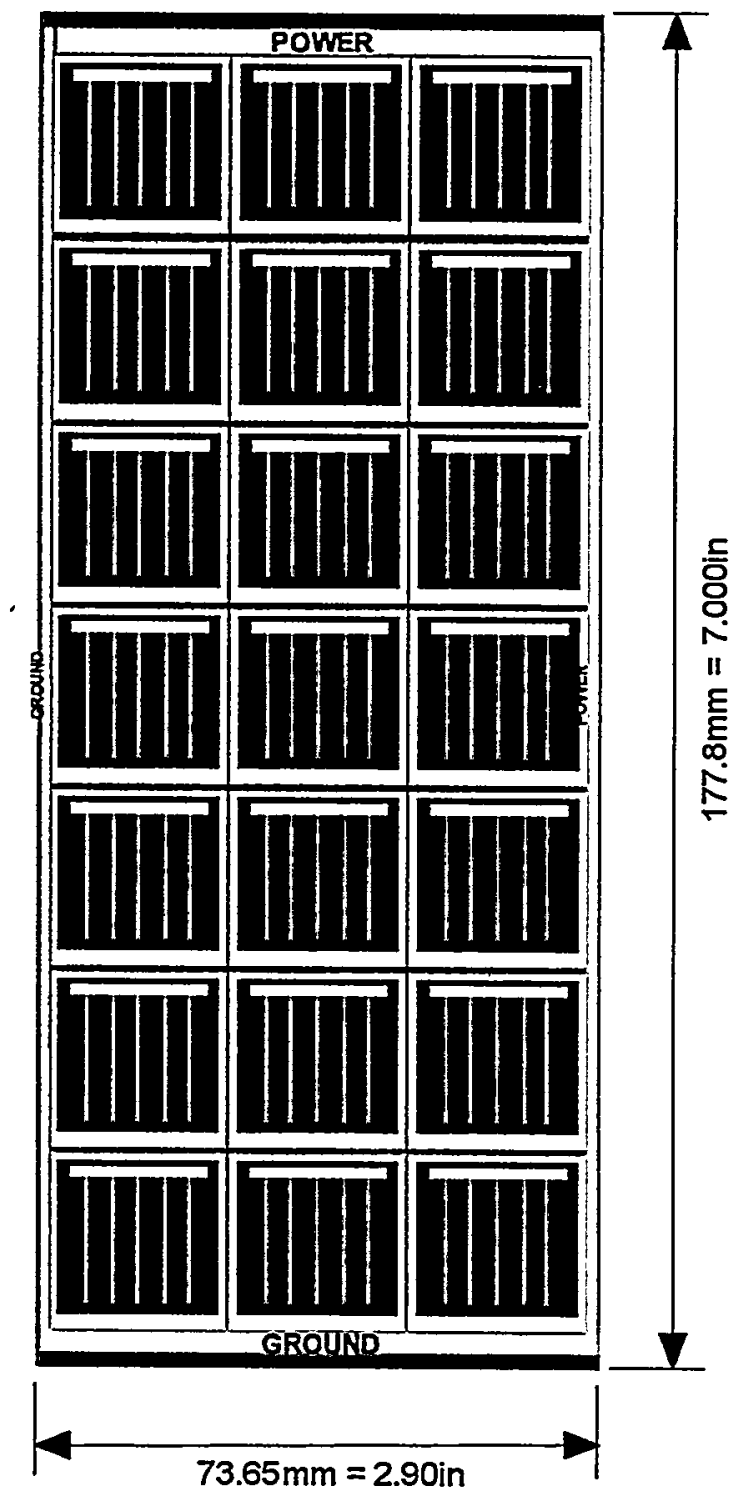

Figure 11. Unit PV panel.for the 7-inch octagon. 
Under AM0 illumination the current in a single cell would be close to $120 \mathrm{~mA}$, as before, so the current in three of these strings wired in parallel is estimated at approximately $0.36 \mathrm{Amp}$, at roughly 7 volts for GaAs cells and about 4 volts for silicon cells. An example of a foldout configuration for an octagon shaped satellite is shown in Fig. 12.
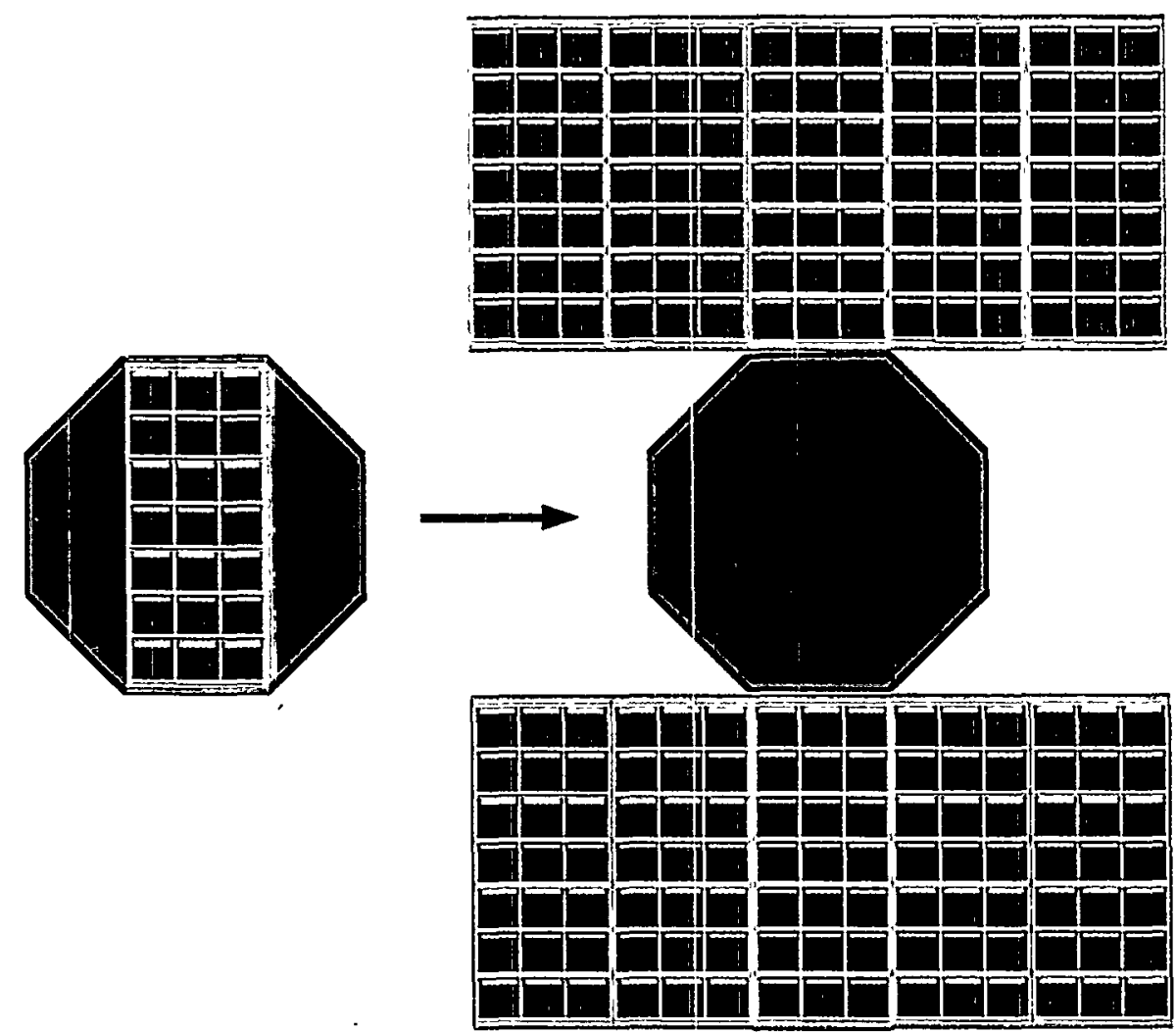

Figure 12. Example of a foldout configuration for the 7-inch octagonal satellite.

Since there are ten panels, at $0.36 \mathrm{Amp}$ per panel, the current for this configuration would be about 3.5 amps.

An alternative configuration which doubles the number of panels to twenty and hence doubles the current to 7 Amps is shown in Figure 13. The primary difficulty with the foldout scheme in Fig. 13 is that of symmetry. The order of foldout is important. The first foldout from the flat sides could be done simultaneously with net momentum reaction near zero. The subsequent foldout of the four panels from each initial panel would have to be done simultaneously also; or it could proceed with the top/left and bottom/right simultaneously and proceed to the other two. This is clearly a more complicated configuration than in Fig. 12. 

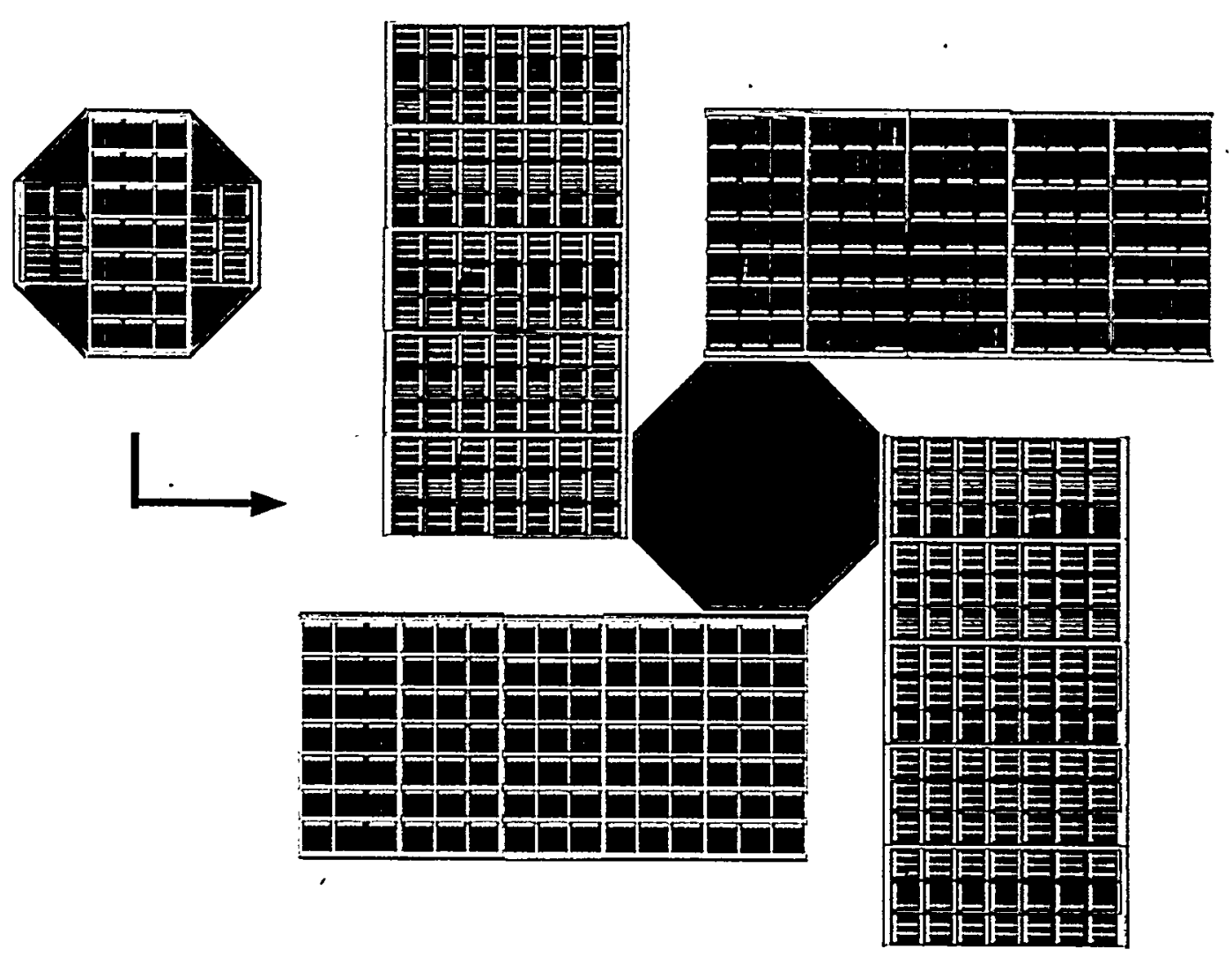

Figure 13. Alternative foldout configuration which doubles the current to 7 Amps.

We now proceed to design arrays that make more efficient use of the space on the end of the octagon shaped satellite. The approach is the same as done for the hexagon. In this case, however, the triangular cells are not equilateral. The schematic layout is as shown in Figure 14 and the calculation of cell area is shown in Figure 15. 


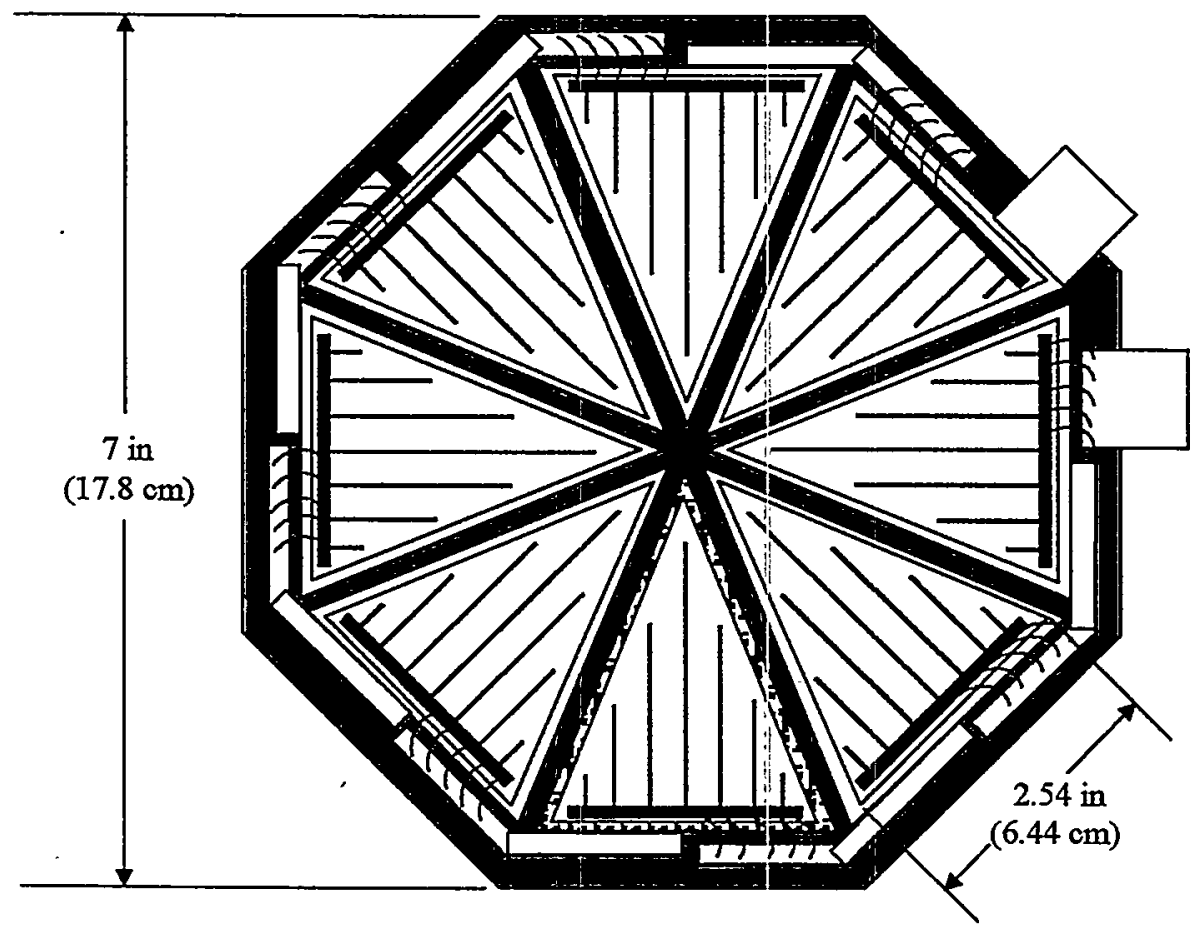

Figure 14. The basic octagon shaped unit array covering the satellite end.

Using the triangular solar cell area of $25 \mathrm{~cm}^{2}$ shown in Fig. 15 and the AMO spectrum short circuit current density of $30 \mathrm{~mA} / \mathrm{cm}^{2}$, the current for the series connection in Fig. 14 multiplies out to $0.75 \mathrm{Amp}$. As before, in the case of the hexagon arrays, the current is increased by exposing more area to the uniform photon flux. This is done by stacking the unit arrays and folding them out. An example of a five-unit foldout is shown in Fig. 16. Connecting all five in parallel would increase the current to 3.75 Amps at 8 volts using GaAs cells and just under 5 volts using Si cells. 


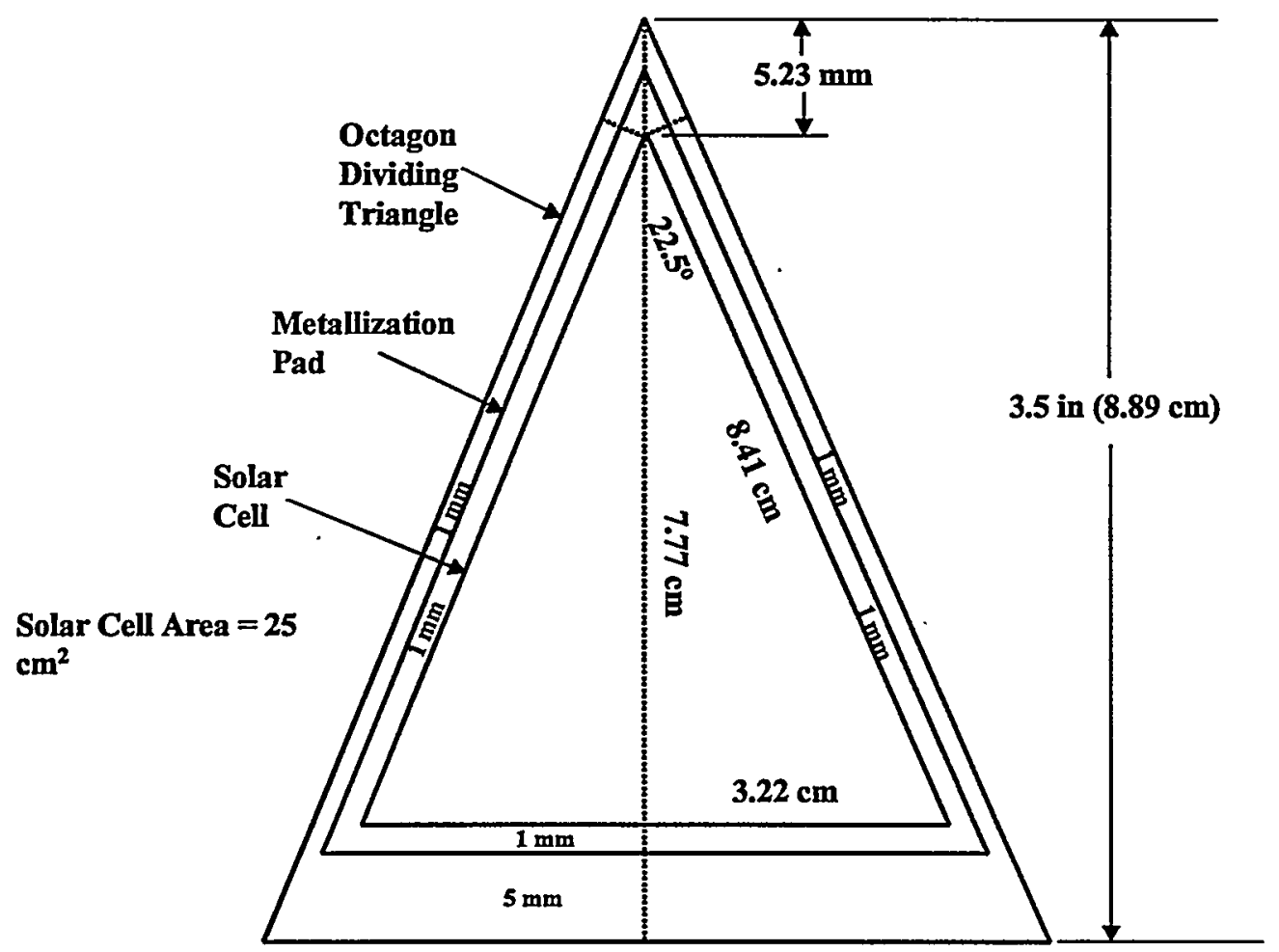

Figure 15. Calculation of solar cell area

\subsection{General Approach to System Definition}

The following discussion is a general approach to determining the nature of a photovoltaic system, given the electrical requirements. These system requirements have not been defined for the nanosatellite project, so we need a prescription for sizing the system.

The example we will use is a 10 volt, $10 \mathrm{amp}$ system, and we will determine the size required to operate it in real time. The approach is to divide the system current by the AM0 short circuit current density, $30 \mathrm{~mA} / \mathrm{cm}^{2}$, to obtain the area of a single junction which will generate the 10 amps. This works out to $333 \mathrm{~cm}^{2}$. In principle, we need 10 of these junctions in series to generate the required voltage. However, a single junction of this area is outside the GaAs fabrication state of the art. If this were a square cell, it would be $18.3 \mathrm{~cm}$ on a side. The device yield on fabrication of a GaAs cell of this size would be vanishingly small, so we have to replace each cell of area $333 \mathrm{~cm}^{2}$ by the appropriate number of cells in parallel connection. If the system is to be made up of GaAs cells, a popular size that is commercially available is $2 \mathrm{~cm} \times 2 \mathrm{~cm}$, or 4 $\mathrm{cm}^{2}$. Dividing this into the $333 \mathrm{~cm}^{2}$ gives 83.25 , or 84 , so replacing each of the $333 \mathrm{~cm}^{2}$ cells in the series connection by a parallel connection of 84 smaller $\left(4 \mathrm{~cm}^{2}\right)$ cells will produce the correct current and voltage. It is more convenient, and equivalent, to form the series connection of 10 of the $4 \mathrm{~cm}^{2}$ cells and then parallel connect 84 of these. The array is shown in Fig. 17. 


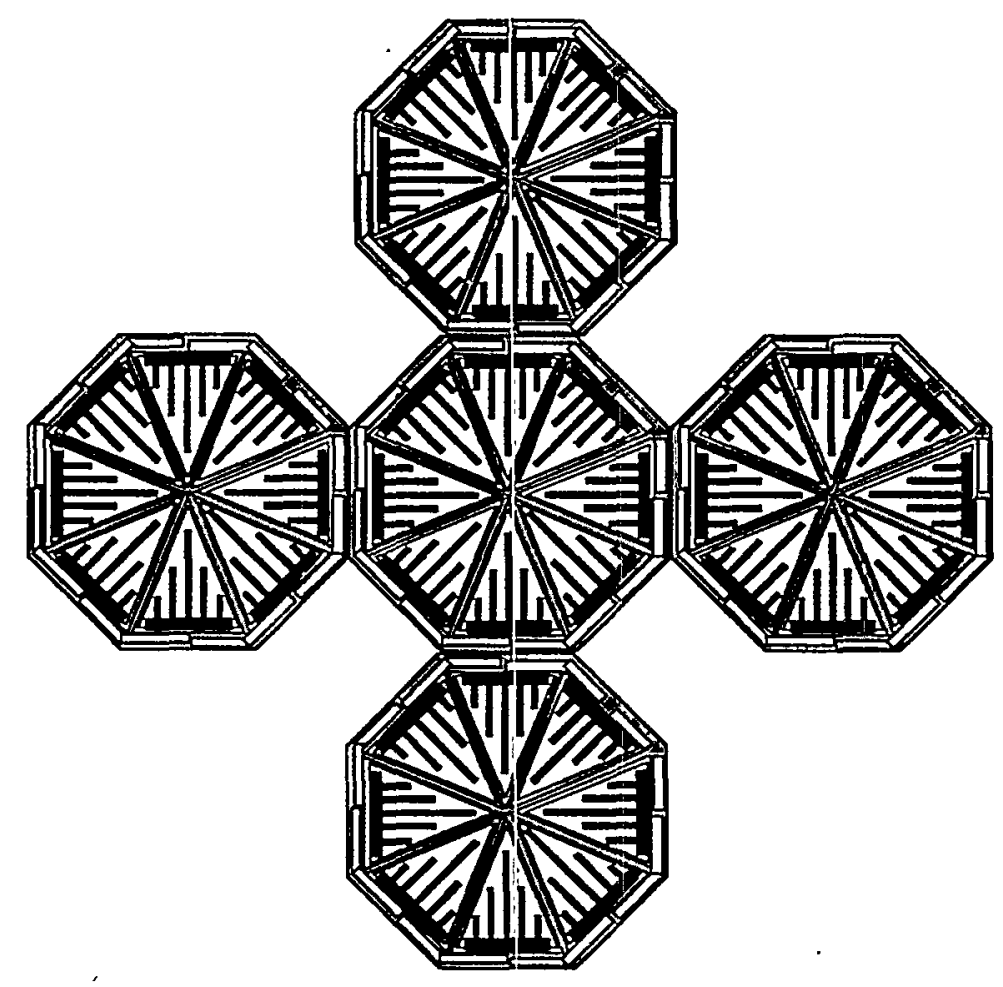

Figure 16. Five-unit foldout configuration

It is important to note that the length of this array is 10 cells long because we need 10 volts and the width, in number of strings, is dependent on the size of cell available. For example, if we were to have available $2 \mathrm{~cm} \mathrm{x} 4 \mathrm{~cm}$, or $8 \mathrm{~cm}^{2} \mathrm{GaAs}$ cells (and they are available), then the width of the array would be 42 instead of 84 . If we were to fabricate the array out of $2 \mathrm{~cm} \times 2 \mathrm{~cm} \mathrm{Si}$ cells, the width of the array would still be 84 (if $30 \mathrm{~mA} / \mathrm{cm}^{2}$ is the AM0 current density) but the length of the array would be 17 cells instead of 10 .

We can generalize what has just been done by plotting the single junction area against the system current. Figure 18 shows three such plots, one for each AM0 current density shown. These are very simple plots, made by drawing a line from the origin through a single point, determined by dividing a given system current by an AMO current density. Their value lies in being able to see graphically that, say a 12-amp system is going to require a junction area of $400 \mathrm{~cm}^{2}$. We can then make another simple plot of the number of cells in a series string against the system voltage. This plot is trivial for GaAs cells because the open circuit voltage is 1 volt per junction. Thus 10 volts correspond to 10 junctions, and so forth. For $\mathrm{Si}$ cells where we take the voltage as 0.6 volts per junction, the plot is different. The number of cells in the 10 volt string would read 16.66667, or 17 cells. 
For high current systems the area required from Fig. 18 will often be larger than can be fabricated with reasonable yield. In these cases, one divides the area by the area of cells that are available to determine the width of the array.

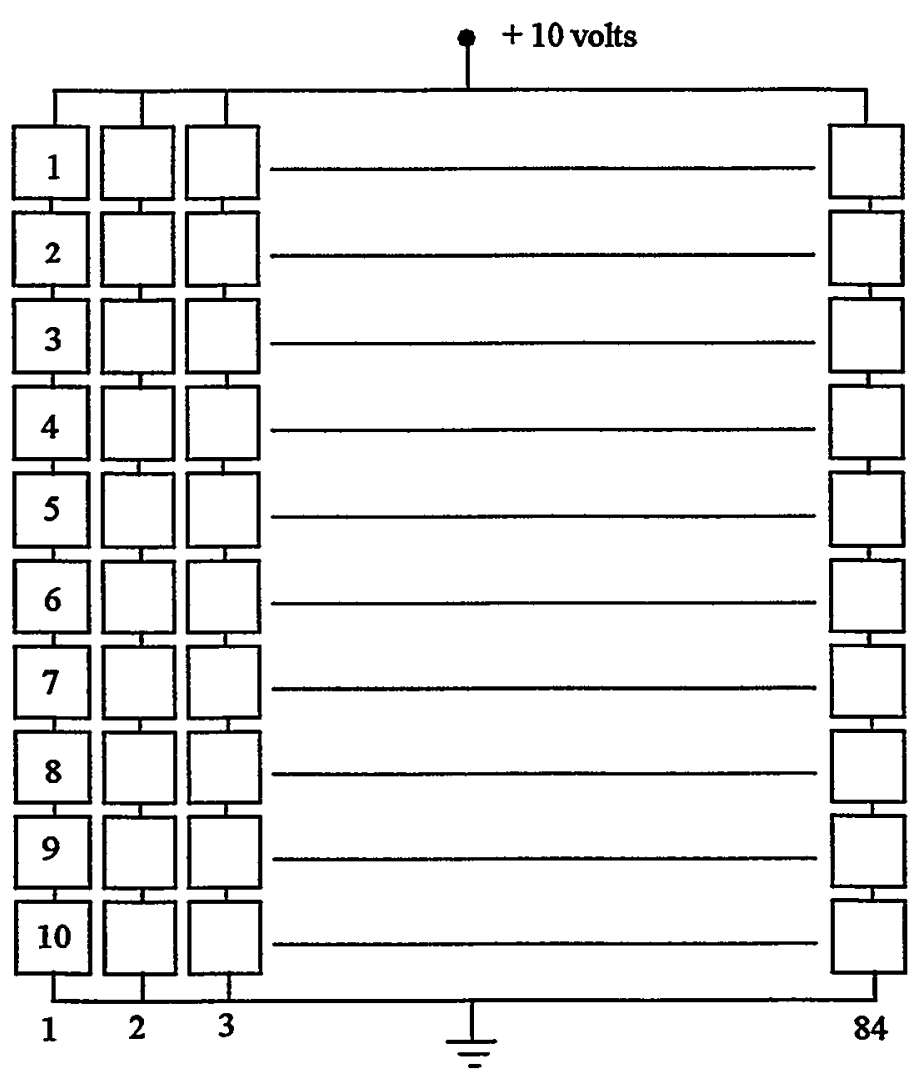

Figure 17. Schematic layout of 84 parallel connected strings of 10 series connected $2 \mathrm{~cm} \times 2 \mathrm{~cm}$ GaAs solar cells. 


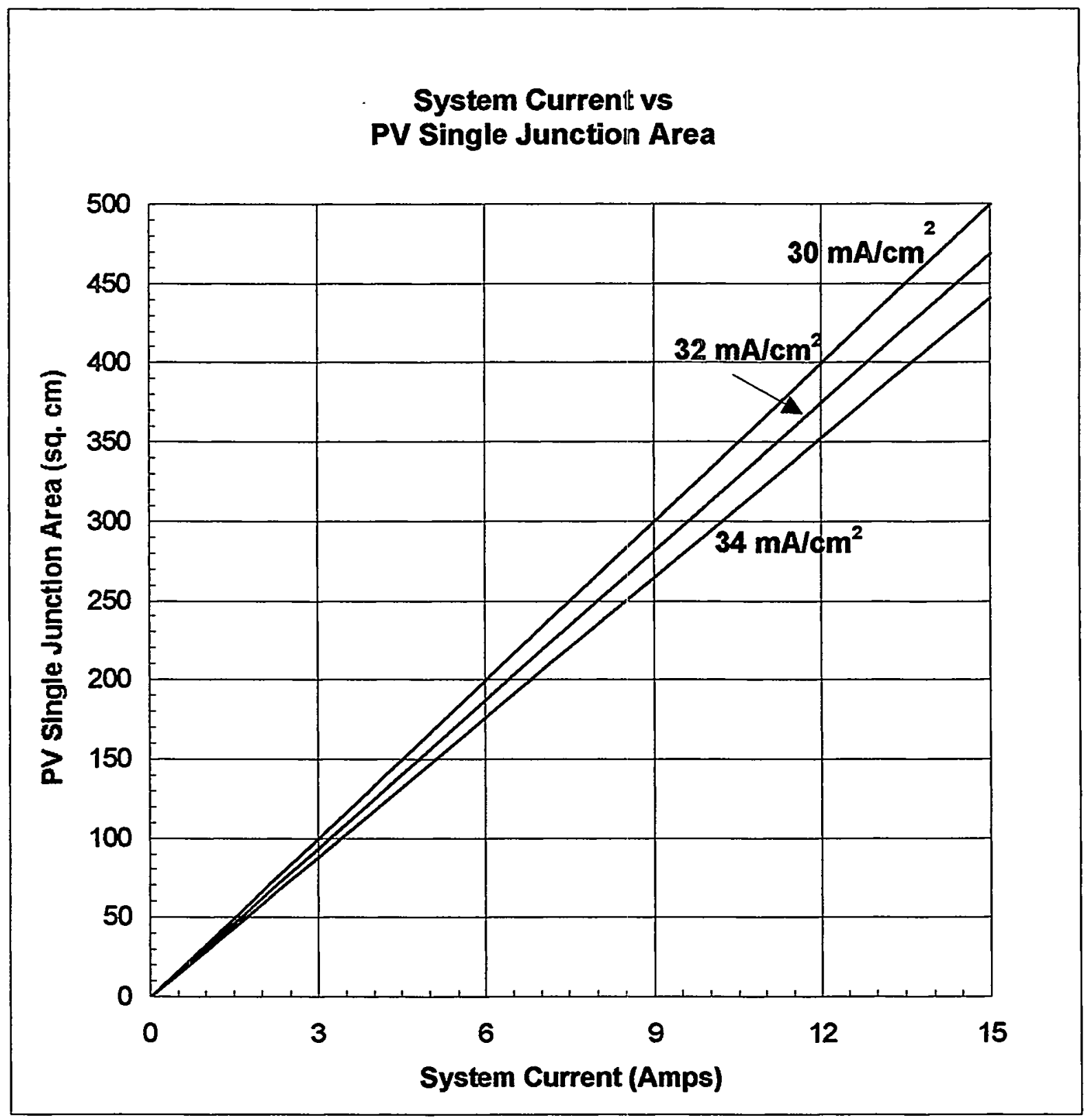

Figure 18. Plot of junction area required to generate a given current.

Finally, we include a 5-volt, 3-amp system made from Si solar cells whose AM0 short circuit current density is $30 \mathrm{~mA} / \mathrm{cm}^{2}$. From Fig. 18 the junction area required is $100 \mathrm{~cm}^{2}$ and Fig. 19 tells us that a minimum of 9 cells in series are needed to exceed the given system voltage. The $100 \mathrm{~cm}^{2}$ area is $10 \mathrm{~cm} \times 10 \mathrm{~cm}$, or about 4 in. $\times 4$ in., and while it might be possible to fabricate them in Si technology, it would probably be a good bit cheaper to go with $2 \mathrm{~cm} \times 2 \mathrm{~cm}$ or $4 \mathrm{~cm} \mathrm{x}$ $4 \mathrm{~cm} \mathrm{Si}$ cells. If we arbitrarily pick the $4 \mathrm{~cm}^{2}$ cells, then the width of the array would be 25 cells across. The length would be 9 cells. Such an array is shown in Fig. 20. 


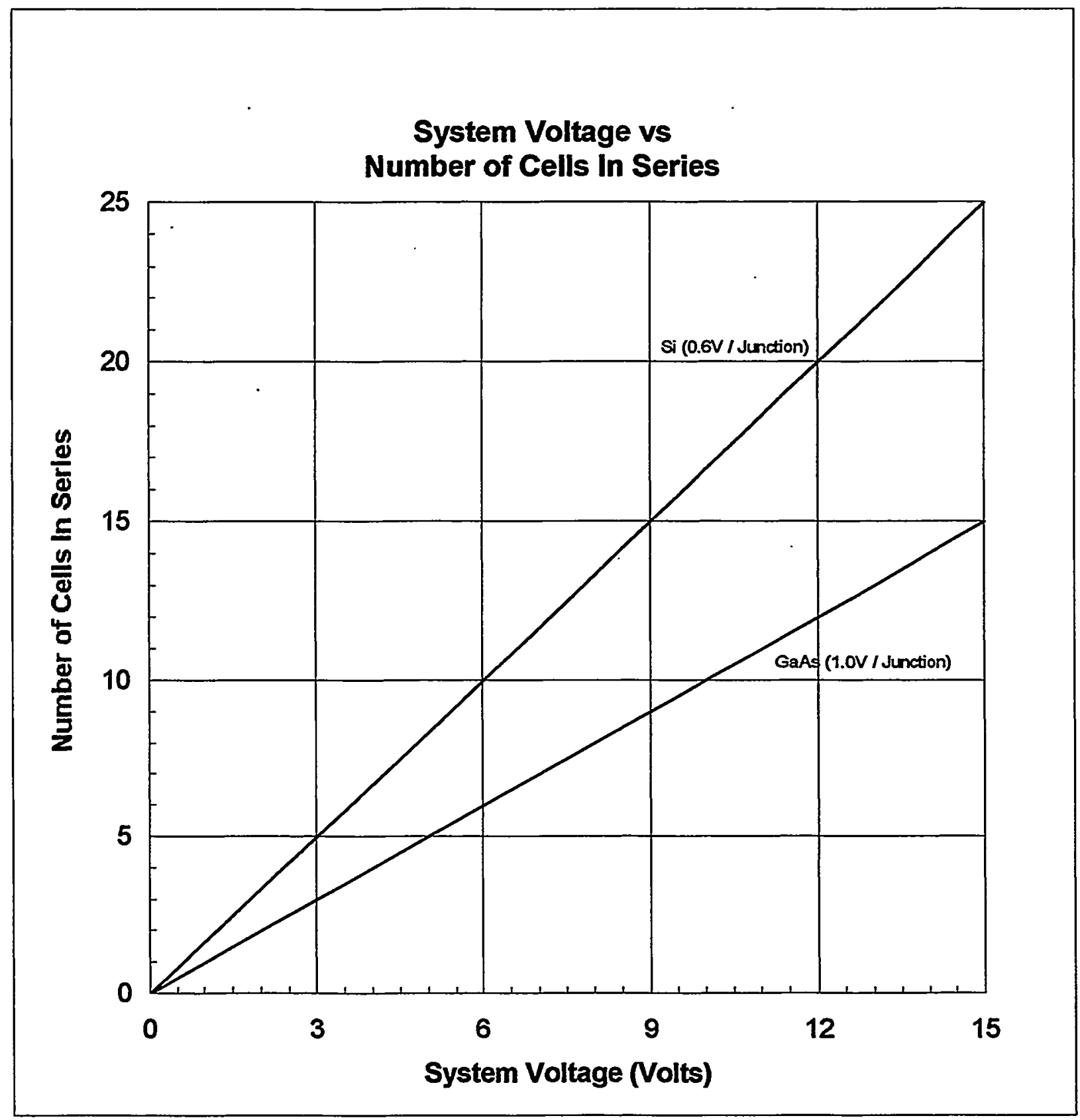

Figure 19. Plot of the number of cells in series connection against the system voltage. 


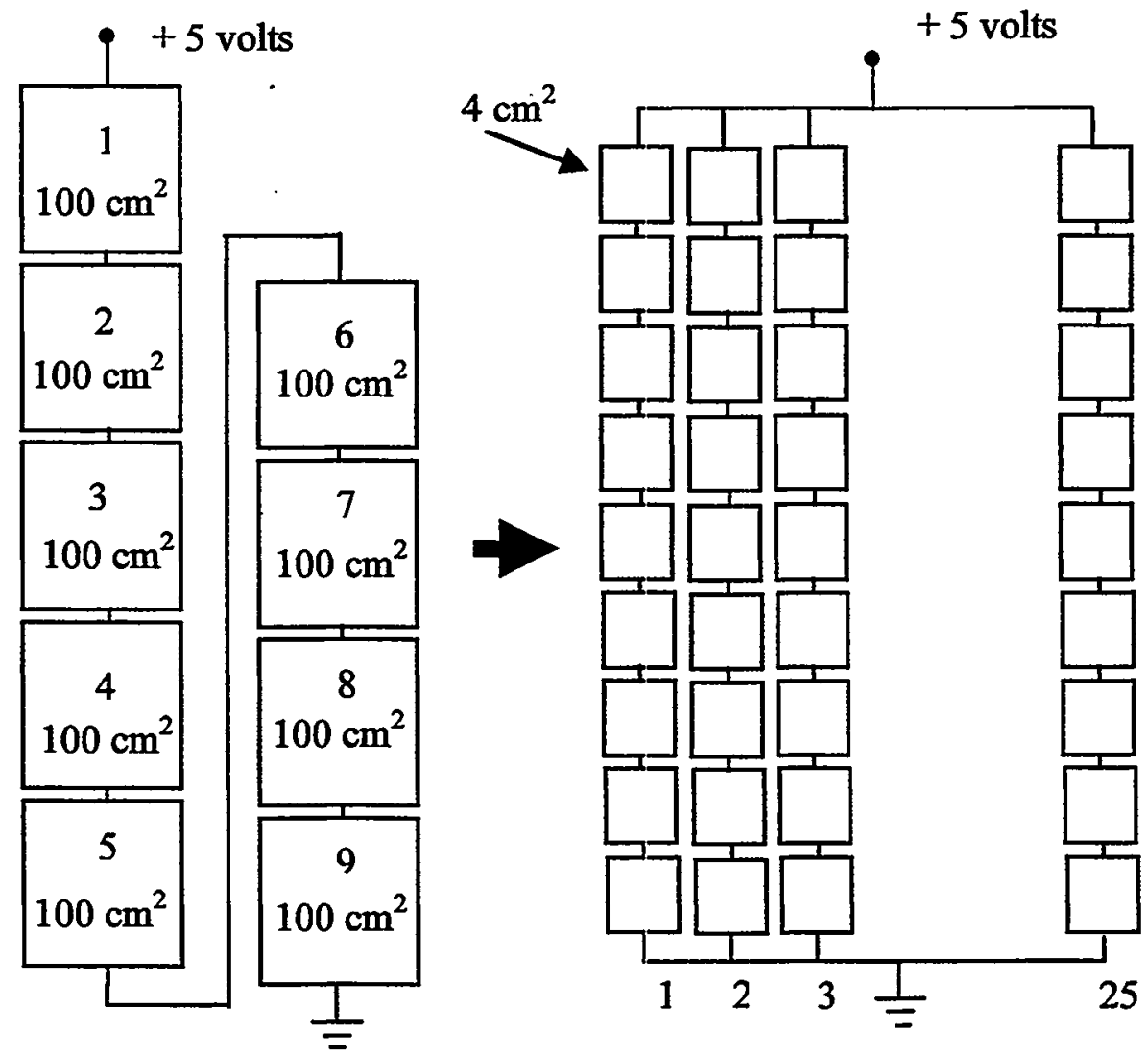

Figure 20. Schematic diagram of a 5-volt, 3-amp system, using $2 \mathrm{~cm} \times 2 \mathrm{~cm}$ Si solar cells.

\subsection{Summary}

With limited information on the current and voltage requirements for the nanosatellite project, we have provided some possible solar power supply geometries and a general way of sizing the system. A prescription has been provided in conjunction with Fig. 18 and Fig. 19 such that when current and voltage requirements become available, one can easily use it to determine the array of appropriate size to fit those requirements.

As was pointed out in the introduction, the PV system required to operate all electronic systems on the satellite in real time is substantially larger than that required to charge batteries which operate low duty cycle electronic systems. Also, if there are control electronics, as indicated in Fig.1, the PV system will have to have the capacity to operate these as well.

The foldout arrays in Figures 5, 12, and 13 are based on use of commercially available $2 \mathrm{~cm} \times 2 \mathrm{~cm} \mathrm{GaAs} \mathrm{solar} \mathrm{cells} \mathrm{available} \mathrm{from} \mathrm{an} \mathrm{aerospace} \mathrm{provider,} \mathrm{such} \mathrm{as} \mathrm{Spectrolab,} \mathrm{Inc.} \mathrm{It} \mathrm{is}$ due to the dimensions chosen for the satellite that seven of these cells in series span the dimension from flat to flat, whether hexagon or octagon. If the final system voltage is 10 volts, either smaller cells will have to be used or we will have to series connect some of the individual strings. If smaller cells are used, more flat panels will have to be folded out to get the required current. Although we have provided systems based on triangular cell designs that efficiently use 
all the area on the end of the satellite, the expense of designing and fabricating custom cells will probably be prohibitive. On the other hand, if the system requirements call for large currents and voltages, custom cells might be required.

Finally, it should be appreciated how much the PV system design changes with system current and voltage. Comparison of Fig. 17 with Fig. 20 will show that the total number of cells required when the system changes from a 5-volt, 3-amp system to a 10-volt, 10-amp system. changes from 125 to 840 . Thus, a precise design for a working system must await a final electronic system design.

\subsection{General Considerations on Satellite Power Conditioning Systems}

\subsection{Power Management and Distribution (PMAD) System Functions}

Traditionally PMAD systems have provided the following four functions [3].

1) Regulation of solar array power. This function ensures proper battery charging and prevents the system load from collapsing the array voltage. First, the battery charge current needs to be regulated during insolation. If this charge current is too small, the system drains the battery and the electrical system just stops working before the end of the defined mission. If the charge current is too high, it overheats the battery, reducing the lifetime. An output voltage limit is also required to prevent battery over-voltage damage.

The bus voltage can be regulated by the battery (the simplest voltage regulator). Historically, bus voltages have been 28 volts, and small dc-dc converters have been used to produce lower usable voltages. The dc-dc converters typically have a wide range of input operating voltage. This input voltage range needs to be within the battery voltage range from full charge to minimum depth of discharge, otherwise battery voltage regulation will be required. Finally, as discussed further below, some kind of peak power tracking will be required because overloading the array will collapse the output voltage. In order to insure stable array operation, its operating point must be at or on the high voltage side of the maximum power point.

2) Provide load fault protection. It is essential for the PMAD system to be able to detect and isolate load faults, even if the complexity of the method is limited to installing fuses in front of the various loads. Current limiting switches could also be used for this function.

3) Housekeeping power for the PMAD hardware. The PMAD power must come from the solar array. Also, the PMAD system must be designed to start up from battery power after launch, or directly from solar power in case the battery system fails.

4) Communication of PMAD health to the spacecraft. In order for new operating parameters to be utilized, the PMAD system must communicate the changed system condition to the spacecraft processor

Button [3] reports an array regulator utilizing an innovative series connected boost unit which looks promising from a low part count standpoint. This regulator is discussed more fully below. 
The above PMAD requirements appear to be for satellites larger than a nanosatellite. How much of the foregoing will be required, or is even possible for our project, remains to be seen. In light of the importance of PMAD systems to satellite operation, it appears that this is an area of investigation of equal importance or more important than merely assembling solar panels. As shown in the previous sections of this report, calculation of approximate values of array open circuit voltage and short circuit current is easy given the known short circuit current density generated by the AMO solar spectrum. As discussed in the next section, historically PMAD has been a large fraction of power, mass and volume of the satellite. The key question is, "Can we build a functional PMAD system with a small enough part count and low enough power demand so that when we add PMAD power demand to the electronic systerns power demand, the required PV array is reasonably compact, and not something that is far larger than the volume of the satellite itself?"

\subsection{Requirements}

In reference 4 Carr makes the case for the reduction of power, mass and volume of the next generation of spacecraft, although it is not clear that he is discussing satellites so small as a nanosatellite. Since the date of the paper is 1995 , it is not clear whether his next generation of spacecraft is a microsatellite or a nanosatellite, but it is irrelevant to the present discussion. The key to reducing the power, mass and volume is miniaturization of the PMAD system. Historically the PMAD system has been the largest consumer of power system allocations.[4] The author goes on to state that the next generation of spacecraft will require reduction in power electronics by $65 \%$, volume by $80 \%$ and part count by $90 \%$. While NASA has supported work in this area, through its Lewis Research Center and Jet Propulsion Laboratory for at least a decade, it is not clear that this work has yet come up with the miniaturization and electronic integration required for the nanosat project. Much of the work in this area is listed in the references for this document. The discussion that follows is a short summary of present day satellite power systems engineering. It is not intended to be exhaustive, but should suffice for our purposes.

Much of the following discussion is taken from Satellite Technology and its Applications, by P. R. K. Chetty [5]. A serious library search has failed to turn up anything more recent. The more recent references are mainly from the IEEE Power Electronics Specialists Conference (PESC), the IEEE Industrial Electronics Conference (IECON), and the Intersociety Energy Conversion Engineering Conference (IECEC), all of which are in the Sandia Library.

Operation of satellite electrical systems using photovoltaic (PV) arrays require power conditioning systems because the I-V curve for the array is non-linear. As schematically shown in Fig. 21, the array can operate as a current source at the short circuit point $\left(I_{s c}\right)$ and as a voltage source at the open circuit point $\left(\mathrm{V}_{o c}\right)$, and all loads in between are allowed. However, as discussed below, some of the loads will result in unstable operation where the array voltage will collapse. For maximum power to be generated, the operating point must be on the knee of the I-V curve where the product of the current and voltage is a maximum, $I_{m p}, V_{m p}$. If the load is purely resistive and equal to $V_{m p} / I_{m p}$, the operating point will be the maximum power point. Reactive loads are dynamic. If a capacitor is charged directly from the array, the load looks like a short circuit initially and as the charge builds up, the operating point moves from $I_{s c}$ around the curve to the open circuit point, $\mathrm{V}_{\mathrm{oc}}$. An inductive load behaves opposite: initially appearing to be an open circuit and as energy is stored in the magnetic field, the operating point moves around to the short circuit point. 
A criterion for determining the stability of array loads was published by Costogue and Lindena in 1976 [6]. The procedure is to superimpose load power vs. voltage characteristics onto the array power vs. voltage characteristics. Then analyze the slopes of the two curves at the intersections. Their criterion is defined by (dP/dV)LOAD >

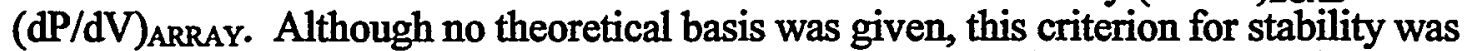
arrived at through numerous measurements on "simulated solar arrays of previous Mariner power subsystems and additional experience on actual solar array powered spacecraft." In Fig. 21, if one applies this criterion to the dotted, constant power line at the intersections with the array power vs voltage curve, one finds the load slope to be zero and the array slope to be positive at point 1 , indicating unstable operation. At point 2 the array slope is negative while the load slope is zero, a stable operation indication. Similar analysis will show that all points to the left of the maximum power point will not satisfy the stable operation criterion and all points to the right will. With peak power tracking, discussed below, the operating point of the array is constrained to the maximum power point and is a constant power feature, so the above analysis applies. We have to force stable operation by being at the maximum power point or on the high voltage side of it A specific system for accomplishing this is discussed below.

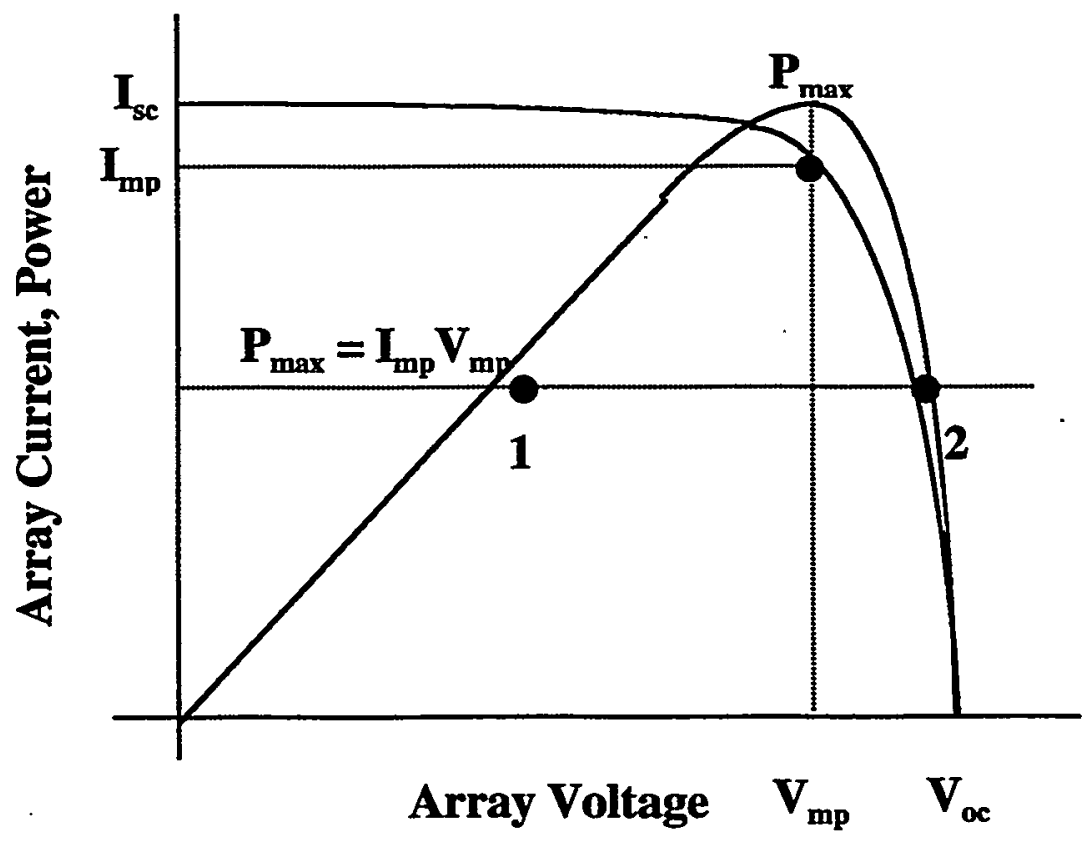

Figure 21. Schematic diagram of a solar array I-V curve.

\subsection{Power Conditioning and Control Systems - General}

The discussion below is taken from [5], but additional information is found in [7], [8], and [9]. Broadly speaking, there are two types of power conditioning and control systems commonly used with satellite photovoltaic systems [5]. They are categorized as dissipative and nondissipative Block diagrams of dissipative systems for a regulated bus and for a nonregulated bus are shown in Figure 22. These systems are also called direct energy transfer systems. 
For satellite power dissipative systems are less than optimum because the bus voltage is fixed by controlling the current in the shunt, thus dissipating part of the solar array power. For the unregulated bus (Fig. 22(b)) the solar array is loaded at the battery charging voltage and the shunt regulator dissipates array power to protect the battery from overcharging at the end of the charging cycle.

The advantages of a regulated bus system [5] are: 1) permits lighter load regulator/converter units, 2) some loads may run directly from the bus, 3) low bus impedance, and 4) solar array working point is fixed. Among the disadvantages are: 1) buffering of units from the bus is limited, 2) dissipation of excess power from the solar array in the shunt regulator, and 3) three types of converters are required. A simple implementation of a shunt regulator is shown in Figure 23.

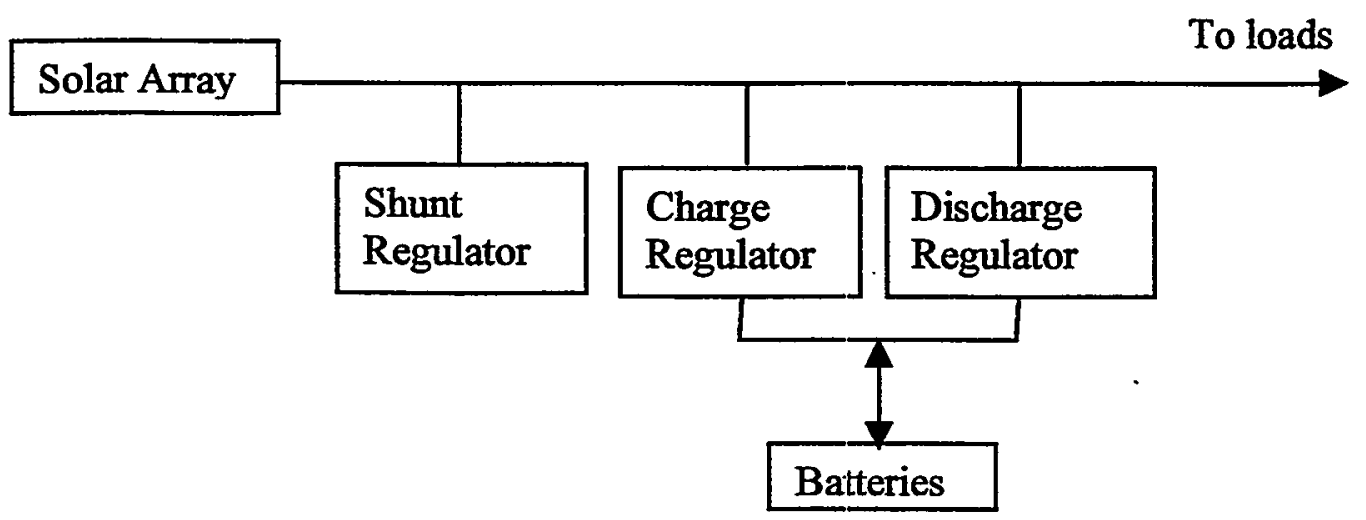

(a)

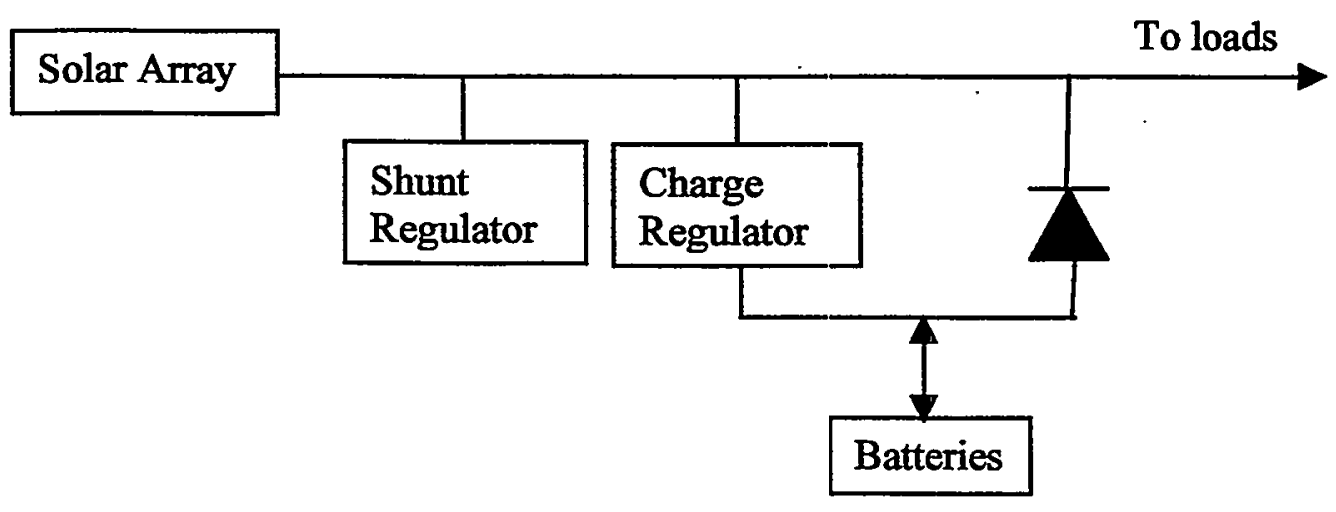

(b)

Figure 22. Block diagrams of dissipative power and control systems.

(a) Regulated bus, (b) Unregulated bus. [5]

The advantages of an unregulated bus [5] are: 1) easier to avoid a single point failure, and 2) units are buffered from noise on the bus. The disadvantages of an unregulated bus are: 1) load regulator/converter units are complex, 2) there is a significant weight penalty, particularly with input filter if unit must work over a wide bus voltage range, and 3) unit switch-on surge currents may prevent operation of the solar array at the maximum power point. 
In spite of the obvious drawbacks, these dissipative power systems were used because the part count was low (neglecting the increased number of solar cells required), meaning low cost and simple implementation.

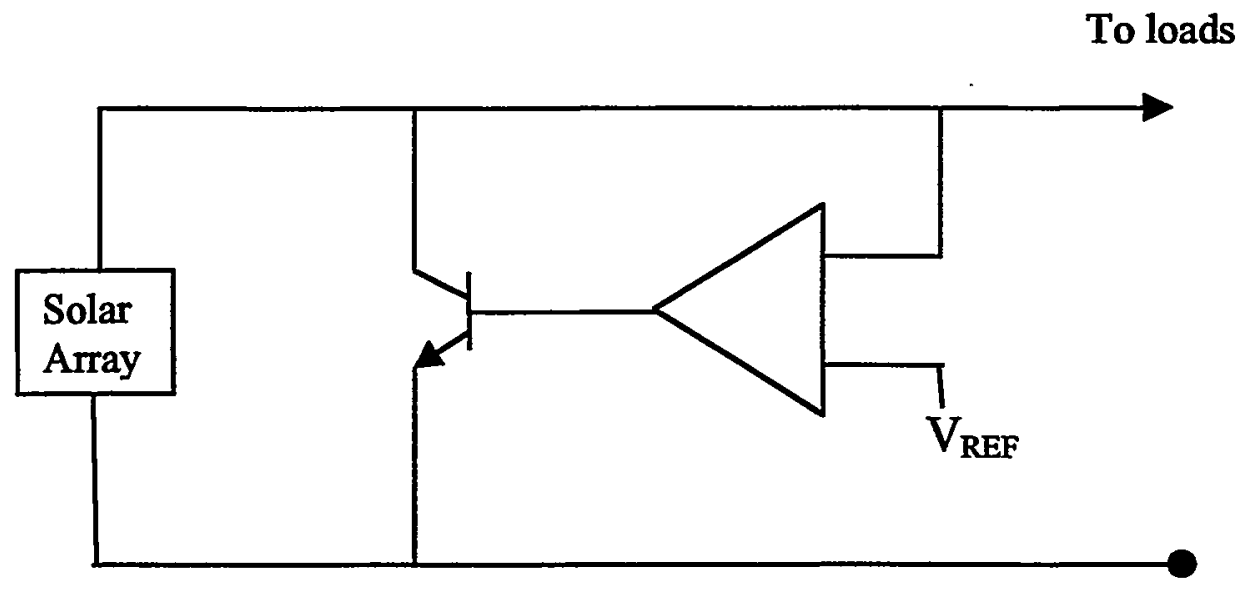

Figure 23. Shunt Regulator. [5]

More modern approaches to satellite power systems are shown in Figure 24. The peak power tracker is any device that constrains the operating point of the solar array at, or near, the maximum power point (MPP). As shown by the list of references, there are a wide variety of methods of peak power tracking, and the range of part count and complexity is large. Most of those listed are probably not suitable for nanosat simply because of cost and complexity (part count). However complex, all these systems accomplish the same thing. They differ in that some are dynamic, which means that they measure some properties of the array, say current and voltage, and adjust the load so the product is a maximum. Others require knowing the current/voltage characteristic of the array. One then stores the current and voltage at maximum power and uses these as reference points. Then the load is adjusted so that the current or voltage closely approximates the reference points.

For systems employing the unregulated bus, each load contains a regulator to level up, down or even invert the voltage. Even with a regulated bus, some loads might require higher or lower voltage than the bus voltage. Thus dc-dc converters are used in front of various loads. Then, according to Fig. 22 and Fig. 24, the bus can be regulated or unregulated irrespective of whether the system is dissipative or non-dissipative. 


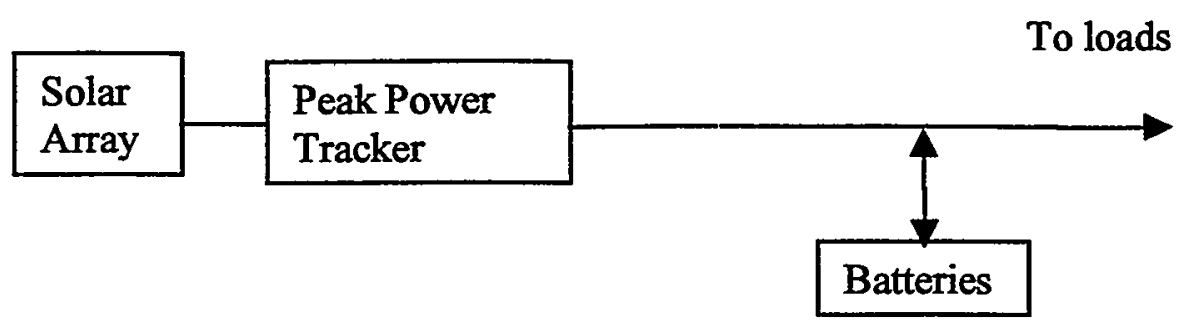

(a)

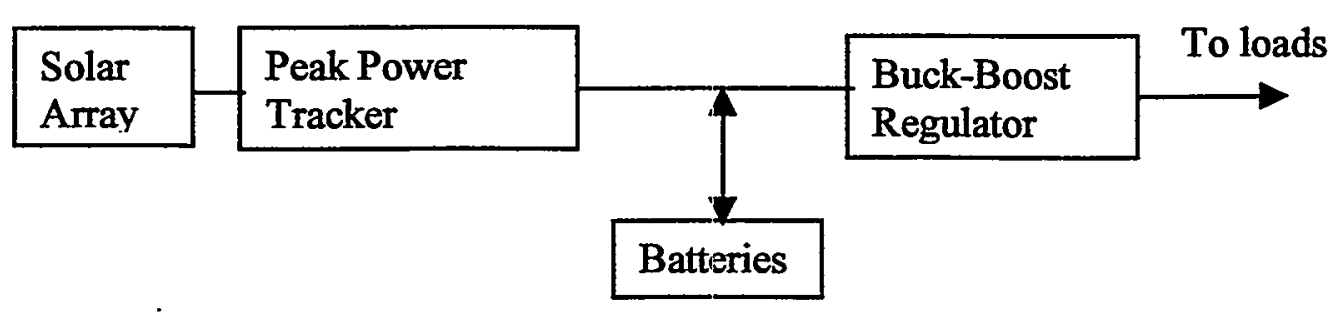

(b)

Figure 24. Non-dissipative power systems. (a) Unregulated bus, (b) regulated bus.

\subsection{Regulators and Peak Power Tracking}

Because of the low losses associated with pulse width modulated regulators, these are usually chosen over linear regulators. It is the system in Fig. 24(b) that would be the best if a regulated bus is required. A simplified schematic of a buck-boost type, switch mode regulator is shown in Figure 25. The output voltage of switch mode power converters is controlled by the duty cycle of the switch, $\mathrm{S}$, in Fig. 25. The circuit element PWM receives a signal from the voltage comparator and, depending on whether the output voltage is below or above $\mathrm{V}_{\mathrm{REF}}$, changes the duty cycle or on-time of switch $\mathrm{S}$. For those unfamiliar with the concept of switch mode converters, their properties are summarized in an Appendix.

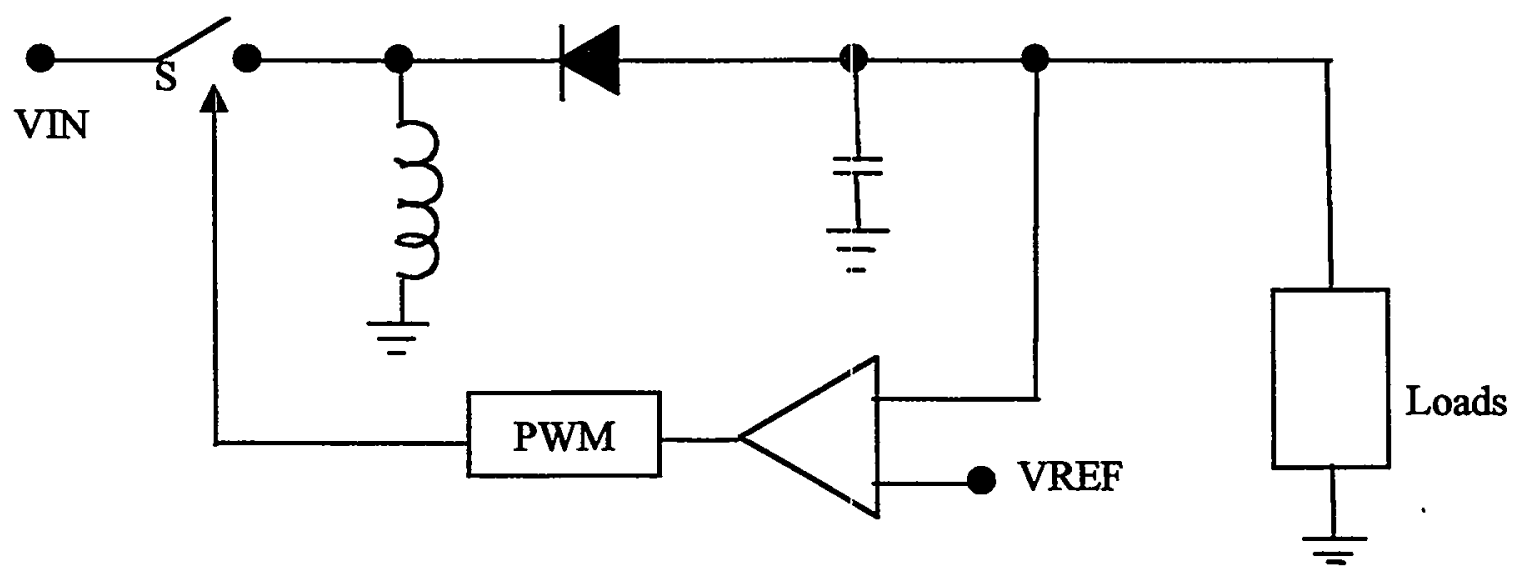

Figure 25. Pulse width modulated buck-boost type voltage regulator. 
In Fig. $25 V_{I N}$ is the solar array output voltage and $V_{R E F}$ should be the maximum power point voltage at the lowest temperature seen by the satellite. This will probably be just before emerging from eclipse. It also needs to be kept in mind that the power to operate this regulator must come from the solar array.

There are a variety of ways that a solar array can be constrained to operate at its maximum power point. Three methods are described below.

21. This principle is based on the almost constant $(0.70$ to 0.75$)$ ratio of the voltage at maximum power to the open circuit voltage of the array over a fairly wide temperature range. To implement this method, a small auxiliary array is maintained in the same environment, but is not loaded, so as to monitor the open circuit voltage. The load is then adjusted to keep the array output voltage at the same fraction of the open circuit voltage.

22. A product of output current and voltage is generated continuously as the solar array is loaded and fed to a peak detector. The loading is reversed when a peak is detected so the system oscillates around the maximum power point.

3) The ac and dc impedances of a solar array are equal at the maximum power point. A ripple current is injected into the array on top of the dc output and both dV/dI and V/I are measured. The load is then changed to keep the two equal.

\subsection{Specific Systems}

In this section a specific PMAD system and an innovative regulator system will be described.

\section{Sunblazer Satellite System}

The paper on the Sunblazer PMAD system was published in 1968 [10], and the reason it might be of interest in the nanosatellite project is its simplicity, meaning low part count, and its size, under $40 \mathrm{lbs}(18 \mathrm{Kg})$. This system was designed to be sent to the opposite side of the sun where radio signals at two frequencies were broadcast through the sun's corona back to earth. The difference in time of flight for the two signals was used to obtain information on the electron density of the sun's corona. This satellite contained a clever method for keeping the solar arrays pointing at the sun. A thin, aluminized mylar "sail" was rolled out to take advantage of the light pressure of photon reflection. The other feature of this satellite system of interest is the relation between the solar array capacity (10-20 watts) and the power required during signal transmission (1600 watts). The bus voltage was 35 volts. This works out to a charging current of about $0.5 \mathrm{amp}$ for the solar array and 46 amps for the intermittent transmission system during operation. Given the big difference between the charging current and the operating current, a sizable energy storage system was required. It consisted of series-parallel connected Ni-Cd cells with parallel connected capacitors. The Sunblazer operated in an orbit with an aphelion of 1 AU (read sun distance) and a perihelion of $0.635 \mathrm{AU}$, which caused a factor of 2.5 difference in array short circuit current. The temperature at perihelion was about $100 \mathrm{C}$ higher than at aphelion, which caused a factor of two difference in open circuit voltage. This wide range in operating parameters makes it impossible to operate at maximum power at orbital extremes, so the peak power tracker was set to the maximum power point at aphelion, the lowest photon flux point and lowest power generation point. To summarize, this satellite requires several of the same requirements as our nanosatellite concept: low part count, roughly the same PV array power output, intermittent transmission, energy storage system, and peak power tracking. The nanosat project has 
the specific advantage of a nearly constant sun distance in low earth orbit, producing a nearly constant photon flux.

The peak power tracker is shown in Figure 26. This is a basic switched mode, boost type converter (see appendix) which tracks the maximum power point. The technique is based on changing the load seen by the array so as to cause the array voltage to oscillate by an amount, $\Delta \mathrm{V}$, and the current to oscillate by an amount, $\Delta \mathrm{I}$. Thus, the operating point is constrained to move between points $\alpha$ and $\beta$ in Fig. 26, and the point $I_{m p}, V_{m p}$ is between them. In the Figure $V_{i}$ is any element that measures the difference between the array voltage and its (peak) value at $V_{\omega}$ and $I_{i}$ is any element that measures the difference between the array current and its (peak) value at $\mathrm{I}_{\beta}$. From Fig. 26, we define

$$
\begin{gathered}
\Delta \mathrm{I}=\mathrm{I}_{\beta}-\mathrm{I}_{\alpha} \\
\Delta \mathrm{V}=\mathrm{V}_{\alpha}-\mathrm{V}_{\beta} .
\end{gathered}
$$

then experimentally,

and

$$
\mathrm{I}_{\mathrm{i}}=\mathrm{I}-\mathrm{I}_{\boldsymbol{\beta}}
$$

$$
\mathrm{V}_{\mathrm{i}}=\mathrm{V}-\mathrm{V}_{\alpha}
$$

Then the switch conditions are: when $I$ reaches $I_{\alpha}$, or $I_{i}$ reaches $-\Delta I$, the switch is closed. This introduces a lower impedance for the array load, which causes the current to increase and the voltage to decrease. When the voltage $V$ reaches $V_{\beta}$, or $V_{i}$ reaches $-\Delta V$, the switch opens, starting the cycle over again. For the original system this process was repeated at about $50 \mathrm{kHz}$, and the values of $\Delta \mathrm{V}$ and $\Delta \mathrm{I}$ were chosen to be about $10 \%$ of the respective values at the maximum power point. For a more modern system voltage comparators might be used for $V_{i}$ and $I_{i}$.

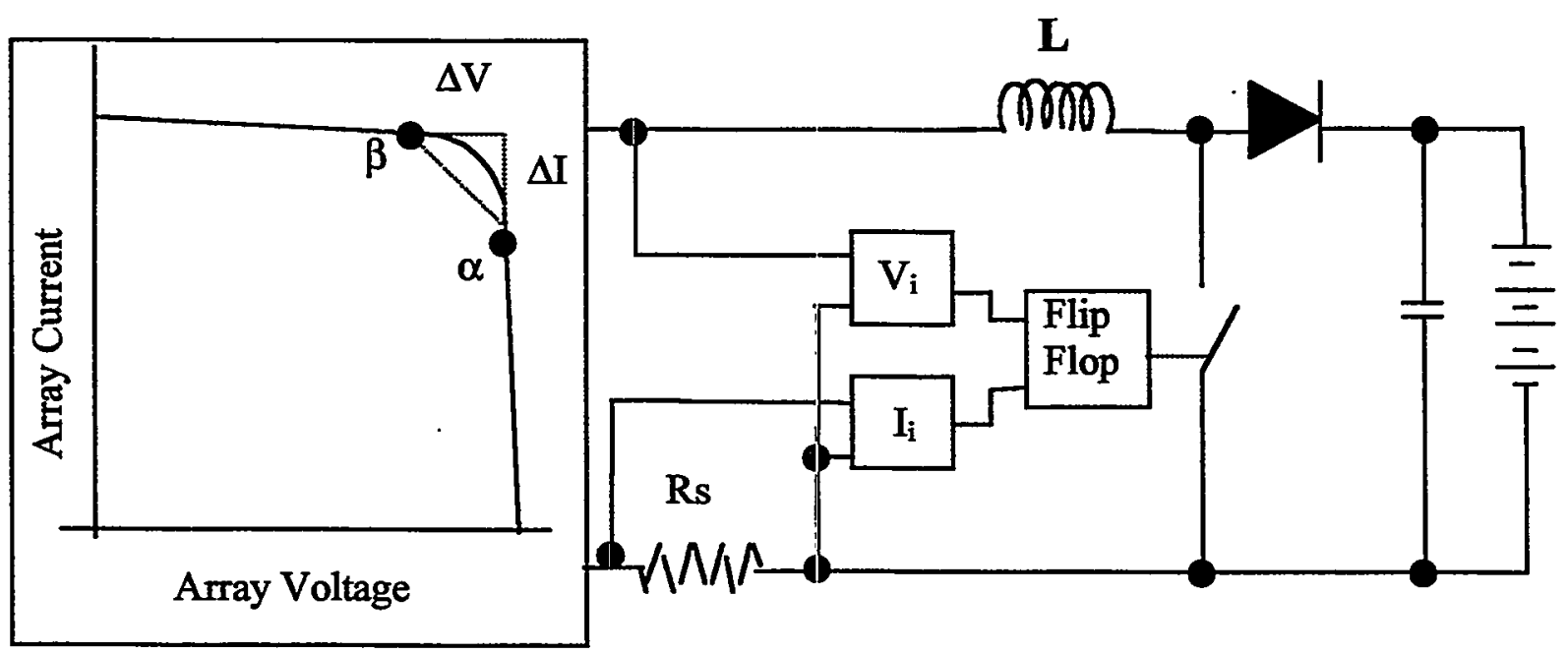

Figure 26. Sunblazer Satellite Peak Power Tracker

The time taken for the system to complete one cycle, $\alpha \rightarrow \beta \rightarrow \alpha$ will depend on the values chosen for $\Delta \mathrm{I}$ and $\Delta \mathrm{V}$. It also depends, for a given coil inductance, on the orbital parameters. For the Sunblazer orbit, something like 2.5 times more current will be generated at perihelion than at aphelion so when $\mathrm{I}_{0:}$ and $\mathrm{I}_{\beta}$ are set at aphelion (lowflux), the value of $\Delta \mathrm{I}$ will be different at perihelion (high flux). Then the frequency will be a 
function of orbital position. For the nanosat in low earth orbit, the photon flux will be approximately constant so we would expect smaller fluctuations in frequency and thus avoid all the complicated analysis in [10]. The frequency, given by Eq. (11) of [10], is

$$
F=\left(V_{0} / L \Delta l\right)\left(1-\left(V_{0} / E\right)\right),
$$

where $V_{0}$ is a voltage between $\alpha$ and $\beta$ (not necessarily $V_{m p}$ ) that the system operates around, $\mathrm{E}$ is the battery voltage, $\mathrm{L}$ the coil inductance, and $\Delta \mathrm{I}$ is defined by Eq. (1). Therefore, we are free to pick a frequency that will minimize losses and solve Eq. (5) for the optimum coil inductance. The point is that the orbital parameters for nanosat present us with a much easier problem than faced by the designers of Sunblazer.

Finally, an even simpler circuit is offered in which the elements $V_{i}, I_{i}$ and the flip-flop are replaced by all passive components, resistors, a diode and capacitors. While this system has not been analyzed in detail here, if it would work, it is an attractive alternative because it would be more resistant to degradation by the radiation environment. The switch itself could be a field effect transistor which, while still a semiconductor component, has far higher radiation tolerance than a bipolar transistor (the original switch).

\section{Series Connected Boost Unit.}

Button [3] has developed a photovoltaic array regulator module with a small part count using a Series Connected Boost Unit (SCBU), invented and patented by Beach and Brush [11]. The sequence of circuits leading to the SCBU are shown in Fig. 27.

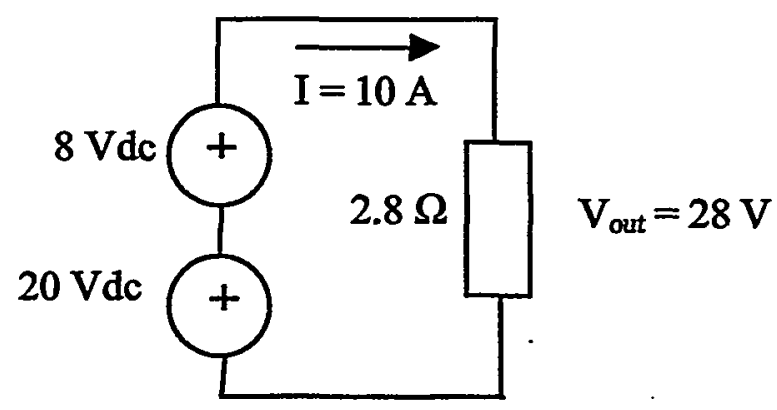

(a)

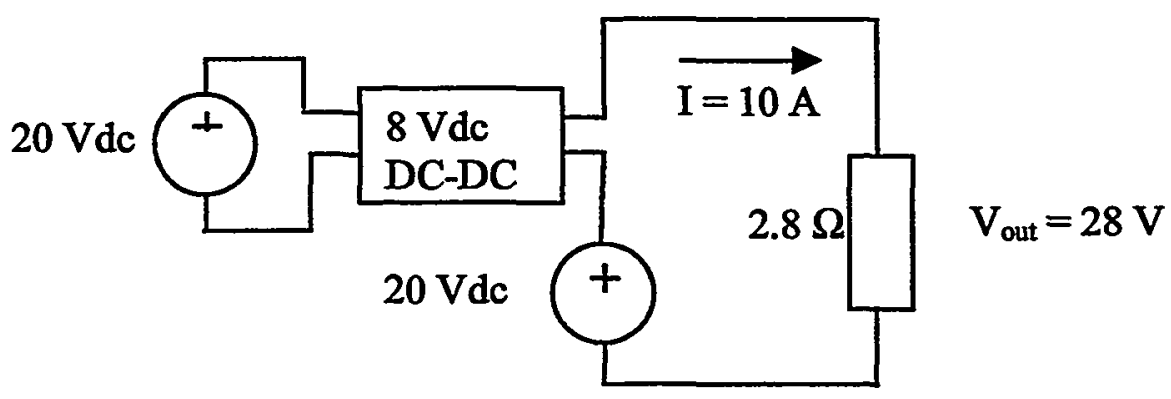

(b) 


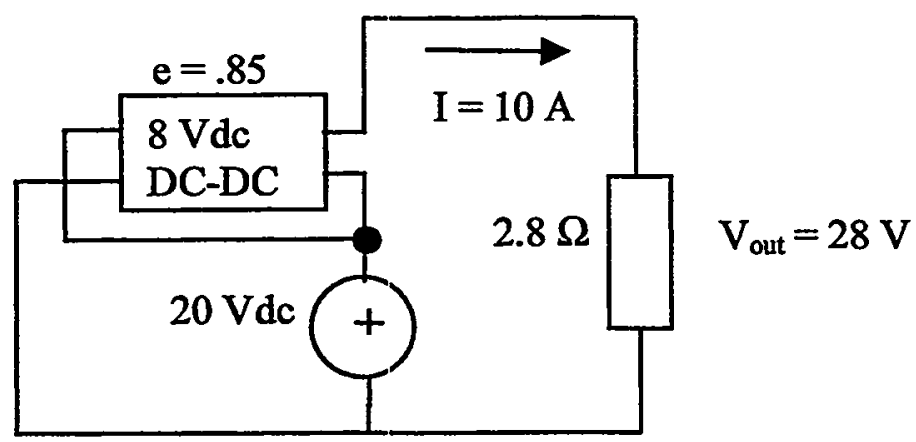

(c)

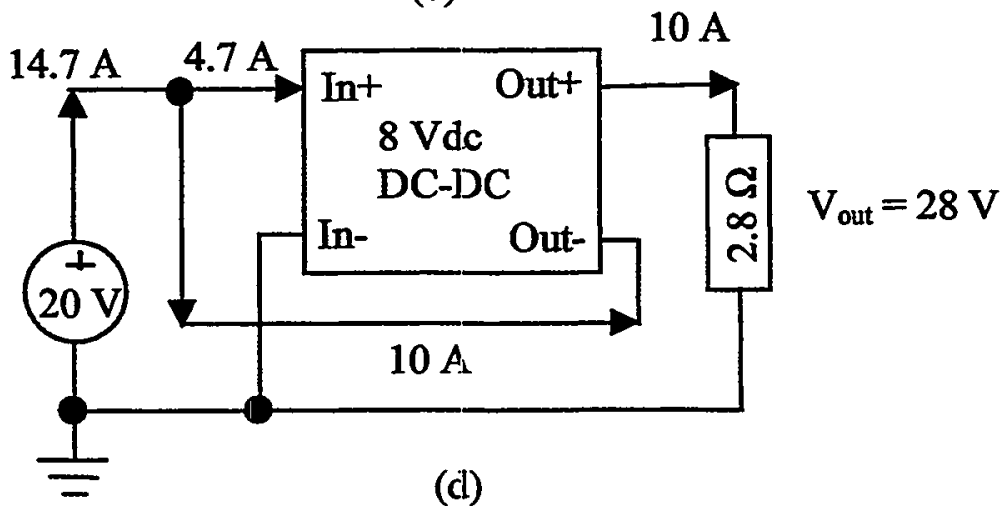

Figure 27. Sequence of circuits resulting in an $8 \mathrm{Vdc}$ boost to the input power supply.

If one connects a $20 \mathrm{Vdc}$ power supply in series with an $8 \mathrm{Vdc}$ power supply and connect the pair across a $2.8 \Omega$ load, the output voltage is obviously $28 \mathrm{Vdc}$ and the current is 10 A. The next step is to replace the 8 Vdc power supply by a dc-dc converter as in Fig. 27 (b). This converter has an input voltage range of 16-32 Vdc, an average efficiency of $85 \%$, an output voltage of $8 \mathrm{Vdc}$, and an output current rating of $10 \mathrm{~A}$. As shown in (b), the converter is powered by a separate $20 \mathrm{Vdc}$ power supply; but since the dc-dc converter is isolated, a single power supply can be used to power both the converter and the load, as in (c). The input current for the dc-dc converter can be obtained from the output power and efficiency,

$$
P_{\text {in }}=P_{\text {dd }} / \mathrm{e}=(8 \mathrm{Vx} 10 \mathrm{~A}) / .85=94 \mathrm{~W},
$$

and

$$
\mathrm{I}_{\mathrm{dc}}=\mathrm{P}_{\text {in }} / \mathrm{V}_{\text {in }}=94 \mathrm{~W} / 20 \mathrm{~V}=4.7 \mathrm{~A}
$$

Finally, in part (d) the circuit in part (c) is redrawn showing the dc-dc converter in series with the 20 Vdc source and the resulting output voltage is boosted by 8 volts.

The efficiency of the SCBU can be quite-high because it does not process all of the power. Efficiencies of $94 \%$ to $98 \%$ have been measured in the lab, and these high efficiencies can be obtained with moderately efficient dc-dc converters, $75 \%-85 \%$. This 
will allow use of relatively inexpensive, off the shelf components. Following [3] we can analyze the efficiency of the SCBU. The SCBU efficiency is given by,

$$
\mathrm{e}_{\text {sbcu }}=\mathrm{P}_{\text {out }} / \mathrm{P}_{\text {in }}=\left(\mathrm{V}_{\text {out }} \mathrm{I}_{\text {out }}\right) /\left(\mathrm{V}_{\text {in }} \mathrm{I}_{\text {in }}\right) \text {, }
$$

where $\mathrm{V}_{\text {out }}$ can be written,

and

$$
\mathrm{V}_{\text {out }}=\mathrm{V}_{\text {in }}+\mathrm{V}_{\text {boost }}
$$

$$
\mathrm{I}_{\text {in }}=\mathrm{I}_{\text {out }}+\mathrm{I}_{\mathrm{dc}} \text {, }
$$

where $I_{d c}$ is the dc-dc converter input current. The input current can be obtained from the output power,

$$
P_{d c}=V_{\text {boost }} I_{\text {out }} \text {, }
$$

and

$$
I_{d c}=P_{\text {in }} / V_{\text {in }}=P_{d d} / e_{d d} / V_{\text {in }}=\left(V_{\text {boost }} I_{\text {out }}\right) /\left(e_{d c} V_{\text {in }}\right)
$$

If we substitute Eq. (10) into Eq. (8) and simplify, we get

$$
I_{\text {in }}=I_{\text {out }}\left\{1+\frac{V_{\text {boost }}}{e_{\text {dc }} V_{\text {in }}}\right\} \text {. }
$$

If we now substitue Eq. (7) and Eq. (11) into Eq. (6) for the SCBU efficiency, we get,

$$
\mathrm{e}_{\mathrm{scbu}}=\frac{\mathrm{V}_{\text {in }}+\mathrm{V}_{\text {boost }}}{V_{\text {in }}+V_{\text {boost }} / \mathrm{e}_{\mathrm{dc}}} .
$$

The SCBU efficiency is only modestly affected by the efficiency of the dc-dc converter. The key is the amount by which $V_{\text {boost }}$ exceeds $V_{\text {in }}$. The larger this amount is, the more Eq. (12) is dominated by the $V_{\text {boost }} / e_{d c}$ term. If we try to make $V_{\text {boost }}$ too high, the efficiency of the SCBU degrades, which means a larger fraction of the total power is being processed by the SCBU. For example, using $V_{\text {in }}=20 \mathrm{Vdc}, \mathrm{V}_{\text {boost }}=8 \mathrm{Vdc}$, and $\mathrm{e}=.85$, we get $95.2 \%$. If $\mathrm{V}_{\text {boost }}=15 \mathrm{Vdc}$ and everything else is the same, the efficiency drops to $93 \%$ - still not too bad.

This is an interesting concept because its use would allow a smaller solar array, $V_{\text {in. }}$ It might be advantageous to scale down the solar array required and put this kind of dc-dc converter in the satellite. It is a low part count way of boosting the solar array voltage. 


\subsection{Conclusions}

We have presented here a summary investigation of modern satellite power systems engineering. It is concluded that most, if not all, present satellite power systems are probably too large for our nanosat project. For example, the small spacecraft photovoltaic regulator kit of reference 12, measures 6.5" x 9.35" x 3.2", about $195 \mathrm{in}^{3}$. The volume of an 8-inch diameter hexagon (7 in flat to flat) and 7 inches in length is about $300 \mathrm{in}^{3}$. Thus, this regulator would occupy $2 / 3$ the volume of the nanosatellite. Clearly another approach is required.

We have presented the details of a low part count system (Sunblazer) which had some of the same requirements as those of the nanosat and more difficult orbital parameters. This system was implemented with three semiconductor components and an inductor. The author also presents a system using only resistors, capacitors, an inductor and a diode. Except for the diode, this is an all-passive component system which would have superior radiation hardness.

It seems clear that if Sandia intends to play a major role in this new satellite initiative, we need to recognize that it is the total system that needs to be optimized. This system consists of the satellite electronic systems, the PV panels, the peak power tracker, and whatever bus voltage regulators we decide are required. There may be trade-offs that will produce the optimum system. For example, use of a miniature peak power tracker along with a boost regulator may still not produce a bus voltage high enough to operate some of the desired loads. If we cannot use lower voltage electronic systems, we either have to design a larger PV system (more cells in series), or miniaturize a dc-dc converter for specific loads that require voltage in excess of the bus voltage. The central point is that the problem is more complicated than just determining the size of the array required to operate the electronic loads from short circuit current and open circuit voltage calculations. As we have tried to show in the report, the size of the system can change drastically with modest changes in system current and voltage. If we do not approach the problem from a total system point of view, the PV system required to operate the satellite electronic systems and the power conditioning systems could be so large as to be simply impractical. It is suggested that future development effort include assembly of modular solar panels of commercially available GaAs space qualified solar cells, and investigation of system optimization. 


\subsection{References}

1. Mircea Faur, Maria Faur, S. G. Bailey, D. J. Flood, D. J. Brinker, D. R. Wheeler, S. A. Alterovitz, D. Scheiman, G. Mateescu, J. Faulk, C. Gordia, and M. Gordia, "Front Surface Engineering of High Efficiency Si Solar Cells and Ge TPV Cells", Proceedings $26^{\text {th }}$ Photovoltaic Specialists Conference, Sept,30, 1997, p. 847.

2. J. G. Werthen, G. F. Virshup, C.W. Ford, C. R. Lewis, and H. C. Hamaker, " $21 \%$ (one sun, Air mass zero) $4 \mathrm{~cm} 2$ GaAs space solar cells", App. Phys. Lett., 48, 74 (1986).

3. Robert M. Button, "An Advanced Photovoltaic Regulator Module, $31^{\text {st }}$ Intersociety Energy Conversion Engineering Conference (IECEC), p. 519, 1996.

4. Gregory A. Carr, "PMAD for the Next Generation Spacecraft", IECEC, 1995, p. 261.

5. P. R. K. Chetty, Satellite Technology and its Applications, TAB Professional and Reference Books, Blue Ridge Summit, PA 1991.

6. E. N. Costogue and S. Lindena, "Comparison of Candidate Solar Array Maximum PowerUtilization Approaches", $11^{\text {th }}$ Intersociety Energy Conversion Engineering Conference (IECEC), p. 1449, 1976.

7. Michael D. Griffin and James R. French, Space Vehicle Design, American Institue of Aeronautics and Astronautics, Inc., Washington, DC, 1991.

8. P. W. Fortescu and J. P. W. Stark, Eds., Spacecraft Systems Engineering, John Wiley and Sons, New York, 1991.

9. J. K. McDermott, Space Mission Analysis and Design, Ed. Wiley J. Larson and James R. Wertz, Microcosm, Inc., Torrance, CA, and Kluwer Academic Publications, The Netherlands, 1992.

10. Andreas F. Boehringer, "Self-Adaptive dc Converter for Solar Power Supply", IEEE Transactions on Aerospace and Electronic Systems", AES-4, 102 (1968).

11. R. F. Beach and A. S. Brush, "Series Connected Converter for Control of Multi-Bus Spacecraft Power Utility", NASA Disclosure of Invention \#LEW15918-1C, NASA Lewis Research Center, Cleveland, OH, 1993.

12. A. N. Baez, R. C. Lebron-Velilla, M. Mackin, and T. Mer, "The Small Spacecraft Technology Initiative Photovoltaic Regulator Kit Experiment (PRKE)", Proceedings $31^{\text {st }}$ Intersociety Energy Conversion Engineering Conference, P. 513, August 1996.

The following are general references from the newest to the oldest.

13. Tasi-Fu Wu and Yu-Kai Chen, "Modeling PWM DC/DC Converters Out of Basic ConverterUnits", IEEE Trans. On Power Electronics, 13, 870 (1998).

14. Lyon van der Merwe and Gawie J. van der Merwe, "Maximum Power Point Tracking Implementation Strategies, Intemational Symposium on Industrial Electronics, Pretoria,South Africa, 1998, p. 214. 
15. W. Swiegers and J. H. R. Enslin, "An Integrated Maximum Power Point Tracker for Photovoltaic Panels", International Symposium on Industrial Electronics, Pretoria South Africa, 1998,

16. A. Capel, "The Power System of the Multimedia Constellation Satellite for the Skybridge Missions", Proc. 29 ${ }^{\text {th }}$ Intemational Power Electronics Specialists' Conference, 1998, p. 1913.

17. Chihchiang Hua and Chihming Shen, "Study of Maximum Power Tracking Techniques and Control of DC/DC Converters for Photovoltaic Power Systems", Proc. 29 Intemational Power Electronics Specialists' Conference, 1998, p. 86.

18. Chihchiang Hua and Chihming Shen, "Control of DC/DC Converters for Solar Energy System with Maximum Power Tracking", Proc. $23^{\text {rd }}$ International Conference on Industrial Electronics, Control and Instrumentation, (IECON), 1997, p. 827.

19. B. E. O'Mara, "Design and Fabrication of a Prototype 1/2 KW Smart Array Controller", Proceedings $32^{\text {nd }}$ Intersociety Energy Conversion Engineering Conference, 1997, p. 1569.

20. J. H. R. Enslin, M. S. Wolf, D. B. Snyman, and W. Swiegers, "Integrated Photovoltaic Maximum Power Point Tracking Converter", IEEE Trans. On Industrial Electronics, 44, 769 (1997).

21. R. Das, S. Krauthamer, and A. Bulawka, "Smart Integrated Power Circuit Technologies for Photovoltaic System Power Conditioning Applications", Proceedings $32^{\text {nd }}$ Intersociety Energy Conversion Engineering Conference, 1997, p. 1564.

22. M. A. Slonim and D. S. Shavit, "Linearization of the Output Characteristics of a Solar Cell and its Application for the Design and Analysis of Solar Cell Arrays", Proceedings $32^{\text {nd }}$ Intersociety Energy Conversion Engineering Conference, 1997, p. 1934.

23. Yoon-Jay Cho and Bo. H. Cho, “A Digital Controlled Solar Array Regulator Employing the Charge Control", Proceedings $32^{\text {nd }}$ Intersociety Energy Conversion Engineering Conference, 1997, p. 2222.

24. R. H. Wills, "Maximum Power Point Tracking Charge Controllers for Telecom Applications - Analysis \& Economics", 26 ${ }^{\text {th }}$ IEEE Photovoltaic Specialists' Conference, 1997, p. 1109.

25. Chihchiang Hua and Jong Rong Lin, "DSP-Based Controller Application in Battery Storage of Photovoltaic System", Proc. 22nd International Conference on Industrial Electronics. Control and Instrumentation, 1996, p. 1705.

26. R. K. Barry, Jr., "Conversion from Full Array Shunt to Partial Array Shunt Topology For Two Small Explorer-Class, Near-Earth Orbiting Scientific Satellites", Proceedings $31^{\text {st }}$ Intersociety Energy Conversion Engineering, 1996, p. 525.

27. K. E. Shum and C. R. Ashley, "A New Full Shunt Switching Unit for Solar Amay UsingCoupled-Inductor Boost Converter", Proceedings 31st Intersociety Energy Conversion Engineering Conference, 1996, p. 617.

28. P. T. Huynh and Bo H. Cho, "Design and Analysis of a Regulated Peak-Power Tracking System", Proceedings $18^{\text {th }}$ Intersociety Energy Conversion Engineering Conference, 1995, p. 285. 
29. M. Piszczor and M. S. Hirschbein, "Space Power System Requirements for Future NASA Missions.", Proceedings $18^{\text {th }}$ Intersociety Energy Conversion Engineering Conference, 1995, p. 421.

30. A. S. Kislovski, "Power Tracking Methods in Photovoltaic Applications", Twenty Sixth International Power Conversion Conference, Numberg, Germany, 1993, p. 513.

31. D. J. Caldwell, L.T. Bavaro, and P. J. Carian, “Advanced Space Power System with Optimized Peak Power Tracking," Proceedings $26^{\text {th }}$ Intersociety Energy Conversion Engineering, 1991, p. 145.

32. R. W. Bercaw and R. C. Cull, "Electrical System Options for Space Exploration", Proceedings $26^{\text {th }}$ Intersociety Energy Conversion Engineering Conference, 1991; p. 332.

33. P. Jain, J. Bottrill, and M. Tanju, "Considerations of Power Conversion Techniques in Future Space Applications”, Solar Power, 8 , 149 (1989).

34. S. J. Kim, J. R. Lee, and Bo H. Cho, "Large-Signal Analysis of Spacecraft Power Systems", $18^{\text {th }}$ IEEE Photovoltaic Specialists' Conference, 1989, p. 2873.

35. J. Applebaum, "The Quality of Load Matching in a Direct-Coupling Photovoltaic System", IEEE Trans. on Energy Conversion, EC-2, 534 (1987).

36. J. J. Schoeman, J.D. Van Wyk, "A Simplified Maximal Power Controller for Terrestrial Photovoltaic Panel Arrays", Proc. $13^{\text {th }}$ International Power Electronics Specialists' Conference, 1982 , p. 361. 


\section{Appendix}

\section{Switch Mode Regulators}

The following discussion of switch mode regulators closely follows that given by Mitchell ${ }^{\mathrm{A} 1}$.

Switch mode regulators convert unregulated source power to regulated load power using power switching devices. Switch mode regulators are chosen over linear regulators because they are more efficient. There is either current or voltage but not together, so ideally there are no losses.

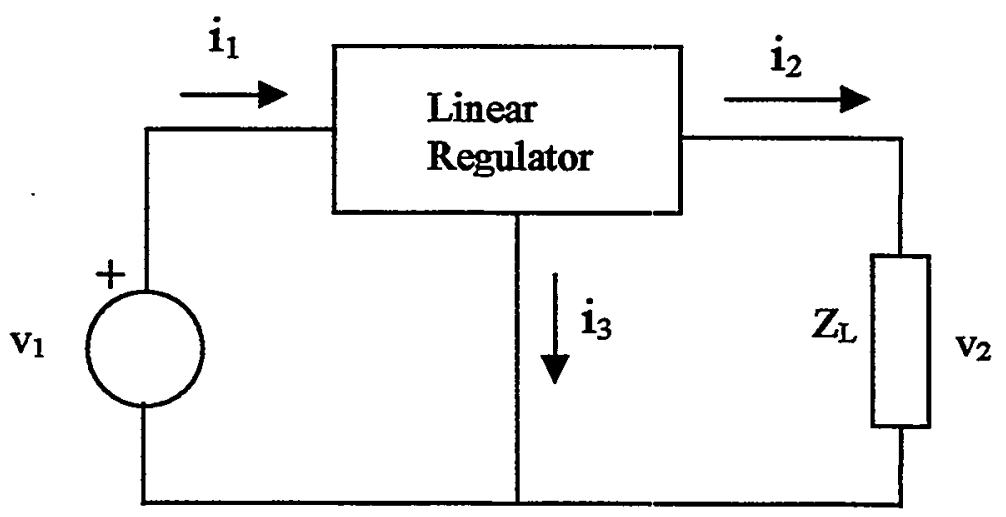

Figure A1. A linear regulator.

The linear regulator shown in Fig. Al can be considered an active voltage divider which maintains a regulated output voltage $v_{2}$ over a range of input voltage $v_{1}$ and load $Z_{L}$. From power considerations the efficiency can be written,

$$
\eta=\left(P_{\text {out }} / P_{\text {in }}\right) \times 100 \%=\left(i_{2} V_{2}\right) /\left(i_{1} V_{1}\right) \times 100 \% .
$$

The maximum theoretical efficiency, which corresponds to $i_{3}=0$, is written,

$$
\eta=\left(v_{2} / v_{1}\right) \times 100 \%, \quad i_{1}=i_{2},
$$

where $v_{2}$ must be smaller than $v_{1}$. For practical regulators $i_{3}>0$, so the constraint on $v_{2}$ is that $v_{2}$ $\left\langle\mathrm{v}_{1}-\mathrm{V}_{\mathrm{T}}\right.$ where $\mathrm{V}_{\mathrm{T}}$ is the minimum voltage required to keep the linear regulator in its active region. This minimum voltage can be substantial. Switching techniques can be used to overcome the limitations on efficiency and the constraint that $v_{2}$ be less the $v_{1}$.

The simplest voltage converter is just a source, a switch, and a load, as shown in Fig. (A2). 

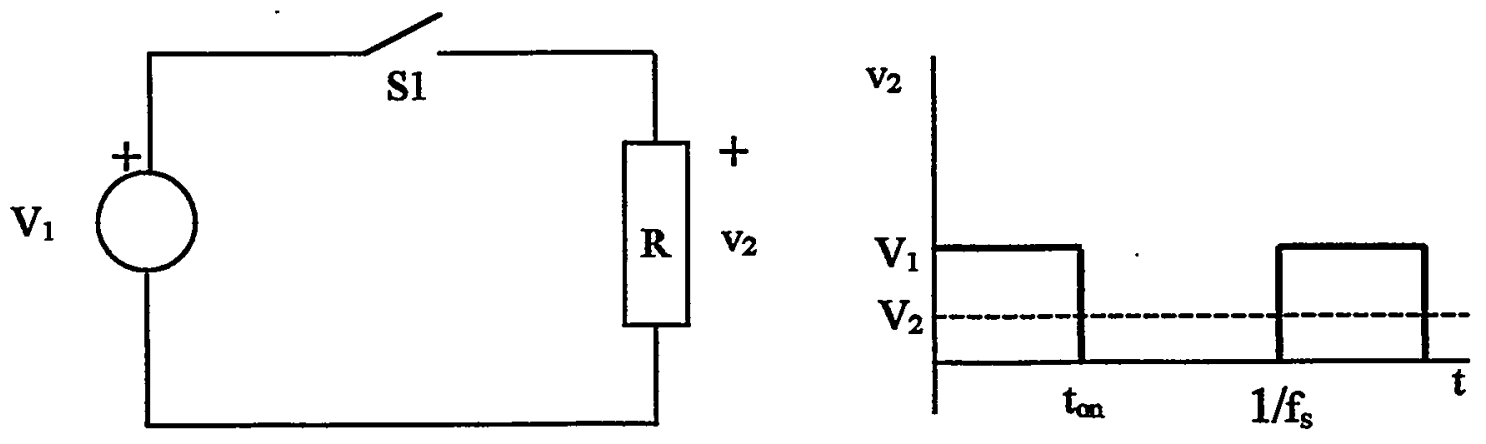

Figure A2. Simplest switching voltage converter.

If we have a load $R$ that requires an average voltage $V_{2}$ and a dc voltage source $V_{1}>V_{2}$, we could just tum the switch on and off in such a way that $V_{2}(a v e)=V_{2}$. If we switch $S 1$ at a frequency $f_{s}$, then the on-time duty factor is just the ratio of $t_{\text {on }}$ to $1 / f_{s}$,

$$
D=t_{o x} /\left(1 / f_{s}\right)=t_{o s} f_{s}=V_{2} / V_{1}
$$

Note that one can get $V_{2}$ arbitrarily close to $V_{1}$ by increasing either $t_{\text {con }}$ or $f_{s .}$. However, as Mitchell points out, most switch mode converters are fixed frequency and the output voltage is regulated by varying $t_{n}$ and, consequently, $t_{\text {off. }}$. If the frequency is high, a voltmeter placed across the load would read $V_{2}$. Unfortunately, this isn't good enough for electronic loads, so the output must be filtered. The first step in filtering is to put a capacitor across the load, but switching a voltage source directly into a capacitor will call for too much current (infinite). So an inductor is placed in series with the load as a non-dissipative means of limiting the source current. However, the inductor current cannot be instantaneous interrupted because the back emf (Ldi/dt) will be infinite. Therefore,opening a switch to interrupt the inductor current supply must be accompanied by closing another switch to provide a continuous path for the inductor current. Thus, the simplest practical voltage converter is a parallel combination of the load resistor and a filter capacitor connected to the voltage source by two switches and an inductor. The number of possible combinations of switch and inductor positions relative to the load and capacitor is three, given by Figure A3. In practice, switches S1 and S2 are combinations of transistors and diodes. For the buck converter in (a), S1 is a bipolar transistor and $\mathbf{S} 2$ is a diode with the anode connected to the low side of the input voltage. For the boost converter of (b), S1 is the transistor and S2 the diode with the anode connected to both the transistor collector and the inductor. For the buck-boost converter $\mathrm{S} 1$ is a transistor and $\mathrm{S} 2$ is the diode with the anode connected to the load.

Circuit analysis leads to the following table of expressions for $V_{2}$ in terms of the duty factor $D$ and the input voltage, $V_{1}$. Thus, the load voltage, $V_{2}$, can be less than $V_{1}$ or greater than $V_{1}$ depending on the arrangement of the two switches and the inductor. In Fig. 26, the Sunblazer system, the array output is fed to the peak power tracking circuit whose output is the input to the boost converter, consisting of the switch, the diode, and inductor. The arrangement is as in Fig. A3 (b) below. 
Table.A1

\begin{tabular}{lcc} 
Converter & \multicolumn{1}{c}{$\mathrm{V}_{2}$} & \\
\hline Buck & $\mathrm{DV}_{1}$ & $\mathrm{~V}_{2}<\mathrm{V}_{1}$ \\
Boost & $\mathrm{V}_{1}(1-\mathrm{D})$ & $\mathrm{V}_{2}>\mathrm{V}_{1}$ \\
Buck-Boost & $-D V_{1} /(1-D)$ & $\mid \begin{array}{l}\mathrm{V}_{2} \mid>V_{1} \text { if } \mathrm{D}>0.5 \\
\left|\mathrm{~V}_{2}\right|<V_{1} \text { if } \mathrm{D}<0.5\end{array}$ \\
\hline
\end{tabular}

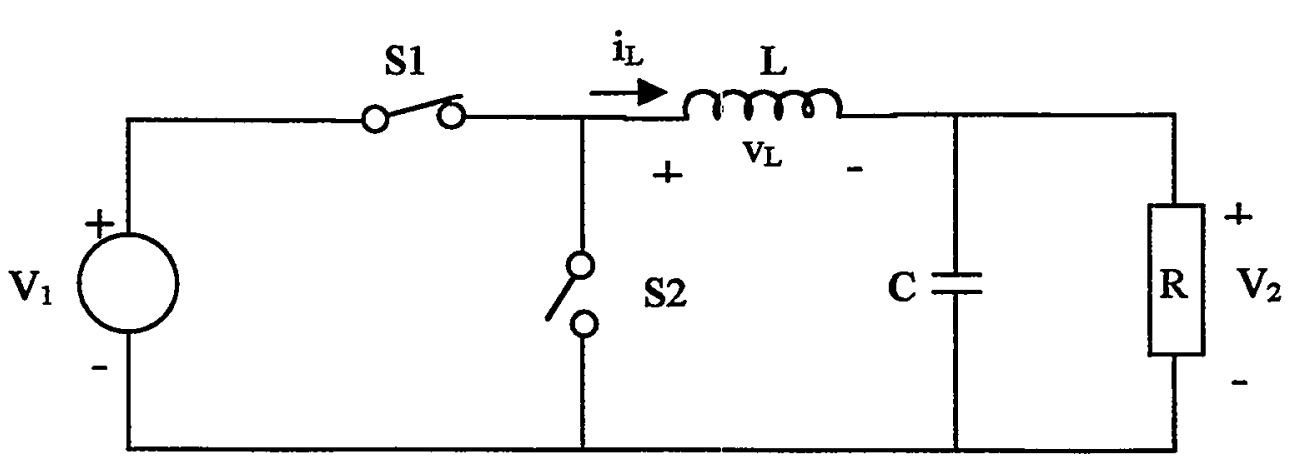

(a)

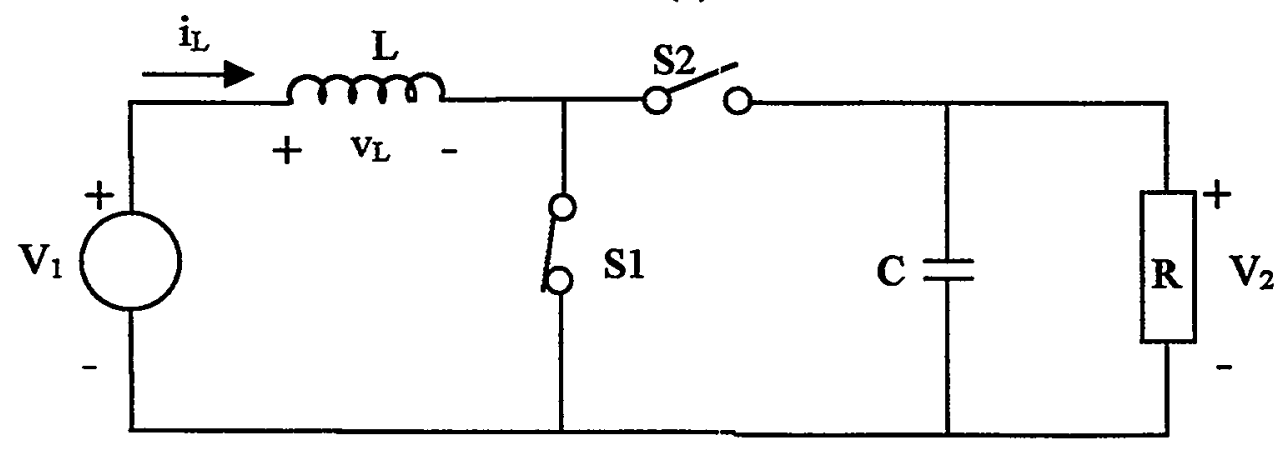

(b)

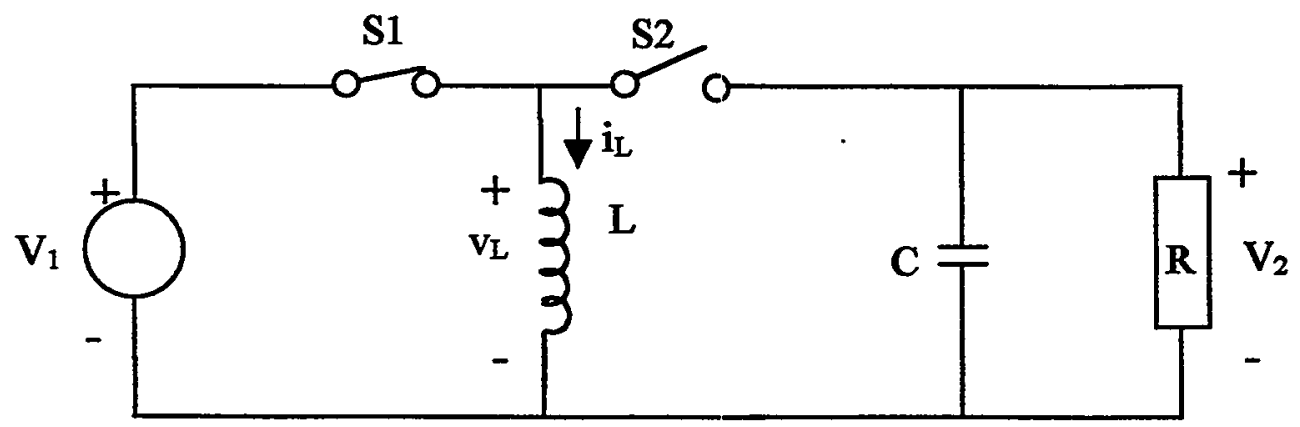

(c)

Figure A3. Switch positions for the three basic converters. (a) Buck, (b) Boost, (c) Buck-Boost. 


\section{Appendix Reference}

A1. Daniel M. Mitchell, DC-DC Switching Regulator Analysis, McGraw-Hill Book Company, New York, 1988. 
Distribution List

$\begin{array}{lrl}1 & \text { MS1079 } & \text { W. David Williams, 1700 } \\ 1 & 0874 & \text { Robert Blewer, 1705 } \\ 1 & 0603 & \text { Steven R. Kurtz, 1713 } \\ 1 & 0603 & \text { Randy J. Shul, 1713 } \\ 1 & 0603 & \text { Thomas E. Zipperian, 1713 } \\ 1 & 0874 & \text { Karl Gass, 1716 } \\ 1 & 0874 & \text { Douglas Greenway, 1716 } \\ 1 & 0874 & \text { Perry Robertson, 1716 } \\ 15 & 0874 & \text { Benny H. Rose, 1716 } \\ 1 & 0614 & \text { David Ingersoll, 2521 } \\ 1 & 0806 & \text { L. Byron Dean, 4616 } \\ 1 & 0806 & \text { Lyndon G. Pierson, 4616 } \\ 1 & 1208 & \text { Jeffery P. Kern, 5705 } \\ 1 & 0965 & \text { J. Lee Schoeneman, 5711 } \\ 1 & 0980 & \text { Dennis A. Reynolds, 5781 } \\ 1 & 0752 & \text { James M. Gee, 6219 } \\ 1 & 9018 & \text { Central Technical Files, 8940-2 } \\ 2 & 0899 & \text { Technical Library, 4916 } \\ 1 & 0619 & \text { Review and Approval Desk, 00111 } \\ & & \text { For DOE/OSTI }\end{array}$

